\title{
Medial Dorsal Hypothalamus Mediates the Inhibition of Reward Seeking after Extinction
}

\author{
Nathan J. Marchant, Teri M. Furlong, and Gavan P. McNally \\ School of Psychology, The University of New South Wales, Sydney, New South Wales 2052, Australia
}

Extinction promotes abstinence from drug seeking. Extinction expression is an active process, dependent on infralimbic prefrontal cortex (ilPFC). However, the neurocircuitry mediating extinction expression is unknown. Here we studied the neural mechanisms for expression of extinction of alcoholic beer seeking in rats. We first examined the pattern of activation in prefrontal cortex projections to medial dorsal hypothalamus (MDH) (i.e., perifornical and dorsomedial nuclei) during extinction expression. Double labeling for retrograde tracer cholera toxin B subunit (CTb) and the neuronal activity marker c-Fos revealed significant recruitment of MDH projecting ilPFC neurons during extinction expression. We then studied the causal role of $\mathrm{MDH}$ in inhibiting alcoholic beer seeking during extinction expression. MDH infusion of the inhibitory neuropeptide cocaine- and amphetamine-regulated transcript prevented extinction expression, showing that $\mathrm{MDH}$ is necessary for extinction expression. Next we examined the pattern of activation in MDH projections to paraventricular thalamus (PVT) during extinction expression. Double labeling for CTb and c-Fos revealed significant recruitment of PVT projecting MDH neurons during extinction expression. We also showed, using triple-label immunofluorescence, that the majority of PVT projecting extinction neurons express prodynorphin, suggesting that actions at $\kappa$ opioid receptors (KORs) in PVT may be critical for inhibiting alcoholic beer seeking. Consistent with this, infusions of a KOR agonist into PVT prevented reinstatement of alcoholic beer seeking showing that PVT KOR activation is sufficient to inhibit alcoholic beer seeking. Together, these findings identify a role for MDH and its ilPFC afferents and PVT efferents in inhibiting alcoholic beer seeking during extinction expression.

\section{Introduction}

Effective extinction of drug craving and seeking is central to achieving abstinence from drug use (Bouton, 2002; Conklin and Tiffany, 2002). Extinction is an active learning process causing inhibition of learned motivations and behaviors (Pavlov, 1927; Rescorla, 2001). The expression of extinction of drug seeking is dependent on neural activity in infralimbic prefrontal cortex (ilPFC) (Peters et al., 2008) and nucleus accumbens shell (AcbSh) (Peters et al., 2008; Millan et al., 2010). However, the neural mechanisms mediating the inhibition of drug seeking observed during the expression of extinction are poorly understood. Understanding these will provide important insights into approaches to promoting abstinence from drug seeking.

Hypothalamus is important for the initiation and termination of motivated behavior (Stellar, 1954; Elmquist et al., 1999). Lateral hypothalamus (LH) initiates motivated behavior (Hoebel, 1979; Kelley, 2004), including feeding (Elmquist et al., 1999). Recently it has been established that LH is also important for reinstatement of drug and reward seeking (Elmquist et al., 1999; Harris et al., 2005, 2007; Marchant et al., 2009). For example, hypothalamic orexin neurons are important for reinstatement of

Received Aug. 4, 2010; revised Aug. 24, 2010; accepted Aug. 27, 2010.

This research was supported by Grants 510199 and 630406 from the National Health and Medical Research Council to G.P.M. and by a University Postgraduate Award to N.J.M. G.P.M. is an Australian Research Council Queen Elizabeth II Fellow (DP0877430). We acknowledge Eun A. Choi and Emily White for their technical assistance.

Correspondence should be addressed to Dr. Gavan P. McNally at the above address. E-mail: g.mcnally@unsw.edu.au.

D0I:10.1523/JNEUROSCI.4079-10.2010

Copyright $\odot 2010$ the authors $\quad 0270-6474 / 10 / 3014102-14 \$ 15.00 / 0$ extinguished drug-seeking (Boutrel et al., 2005; Harris et al., 2005; Lawrence et al., 2006) and inactivation of LH prevents context-induced reinstatement of extinguished alcoholic beer seeking (Marchant et al., 2009). Furthermore food deprivation augments drug self-administration (Comer et al., 1995) and reinstates extinguished drug seeking (Carroll, 1985; Shalev et al., 2000). This indicates a commonality between reinstatement of drug seeking and the neural circuits controlling feeding.

This role for hypothalamus in reinstatement of drug and reward seeking raises the possibility that hypothalamus may likewise contribute to extinction expression. The medial dorsal hypothalamus (MDH), which encompasses perifornical and dorsomedial nuclei, has long been associated with termination of motivated behaviors such as feeding and intracranial selfstimulation (Stellar, 1954; Porrino et al., 1983). More recently, $\mathrm{MDH}$ has been identified as a critical site for inhibition of food intake (Elmquist et al., 1999; Bellinger and Bernardis, 2002), and $\mathrm{MDH}$ neurons show increased activation after injection of satiety factors such as leptin (Elmquist et al., 1998) and cholecystokinin (Kobelt et al., 2006; Chen et al., 2008). Interestingly, ilPFC projects extensively to MDH (Thompson and Swanson, 1998; Heidbreder and Groenewegen, 2003), raising the possibility that $\mathrm{MDH}$ might be an important target for ilPFC contributions to expression of extinction. The MDH, in turn, sends projections to paraventricular thalamus (PVT). PVT is critical for reinstatement of alcohol seeking (Dayas et al., 2008; Hamlin et al., 2009). PVT has extensive projections to basolateral amygdala (BLA), AcbSh, ventral subiculum, and PFC (Christie et al., 1987; Li and Kirouac, 2008; Vertes and Hoover, 2008), and projections from 
PVT to AcbSh are recruited during context-induced reinstatement (Hamlin et al., 2009). Here we used complementary functional and neuroanatomical techniques, retrograde tract tracing, immunohistochemistry for the activity marker c-Fos, and pharmacological microinjections to identify the MDH afferents and efferents recruited during the expression of extinction of alcoholic beer seeking and to study the causal role of $\mathrm{MDH}$ in this extinction expression.

\section{Materials and Methods}

Subjects. Subjects were experimentally naive male Long-Evans rats (250 $350 \mathrm{~g}$ ) obtained from a commercial supplier (Monash Animal Services). After arrival, rats were housed in groups of eight in plastic cages maintained on a $12 \mathrm{~h} \mathrm{light/dark} \mathrm{cycle} \mathrm{(lights} \mathrm{on} \mathrm{at} \mathrm{6:00} \mathrm{A.M.).} \mathrm{The} \mathrm{procedures}$ were approved by the Animal Care and Ethics Committee at the University of New South Wales and conducted in accordance with the National Institutes of Health Guide for the Care and Use of Laboratory Animals (NIH Publication No. 80-23, revised 1996). The procedures were designed to minimize the number of animals used.

Behavioral apparatus. For all experiments, training, extinction, and test were conducted in two sets of four Med Associates chambers. In all chambers $(24 \mathrm{~cm}$ [length] $\times 30 \mathrm{~cm}$ [width] $\times 21 \mathrm{~cm}$ [height] $)$, the front and rear walls as well as the hinged lid were constructed of clear Perspex and the end walls were made of stainless steel. There were two nose-poke holes, containing a white cue-light, located on one side wall of the chamber $3 \mathrm{~cm}$ above the floor. A recessed magazine was located behind a $4 \mathrm{~cm} \times 4 \mathrm{~cm}$ opening in the center of the same wall, between the two nose pokes. All chambers were located in sound and light attenuating cabinets equipped with fans providing constant ventilation and low level background noise. To serve as distinct contexts, the chambers differed in their visual (brightly lit versus dark), tactile (Perspex versus grid floors), and olfactory (rose oil versus peppermint essence) properties. In one set of chambers the floor consisted of stainless steel rods, $4 \mathrm{~mm}$ in diameter, spaced $15 \mathrm{~mm}$ apart (center to center). There was no illumination in these chambers other than that provided by the white cue light recessed in the nose pokes. Dilute rose oil was placed in the bedding beneath these chambers. In the second set of chambers the floors consisted of a Perspex plate. Illumination was provided by a $28 \mathrm{~V}$ house light. Dilute peppermint essence was placed in the bedding beneath the chambers. These two sets of chambers were fully counterbalanced to serve as contexts A and B.

Behavioral testing procedures. The behavioral procedures were identical for all experiments. On the first $2 \mathrm{~d}$, the animals received $20 \mathrm{~min}$ magazine training sessions in both chambers. During these sessions there were 10 noncontingent deliveries of $0.6 \mathrm{ml}$ of the reward [ $4 \%$ alcohol $(\mathrm{v} / \mathrm{v})$ decarbonated beer, or $10 \%$ sucrose] at time intervals variable around a mean of $1.2 \mathrm{~min}$. On the next $7 \mathrm{~d}$, rats received selfadministration training, in context $\mathrm{A}$ for $1 \mathrm{~h}$ per day. During this time, responding on the active nose poke extinguished the nose-poke cue light and triggered delivery of $0.6 \mathrm{ml}$ of the reward to the magazine on an fixed ratio 1 schedule followed by a $24 \mathrm{~s}$ timeout. Responses on the inactive nose poke were recorded but had no programmable consequences. On the next 4 or $5 \mathrm{~d}$, depending on the experiment, rats received extinction training in context B for $1 \mathrm{~h}$ per day. During extinction training, responses on the active nose poke switched off the cue light and triggered the pump but no reward was delivered. All rats were tested $24 \mathrm{~h}$ after the last extinction session. Rats in the retrograde tracing experiments were tested under extinction conditions in the operant chambers (context A or $\mathrm{B}$, depending on their group allocation) for $1 \mathrm{~h}$. These rats were perfused $1 \mathrm{~h}$ after the end of test. Rats in the microinfusion experiments received their corresponding infusion, depending on their group allocation, and then tested for $1 \mathrm{~h}$ under extinction conditions in the operant chambers (context A or B, depending on their group allocation). Experiments with multiple tests also began $24 \mathrm{~h}$ after the last day of extinction. These parameters were chosen based on our past research which shows robust acquisition, extinction, and context-induced reinstatement of responding under these conditions (Hamlin et al., 2006, 2007, 2008).

Retrograde tracing surgery. Before all behavioral testing, rats in the retrograde tracing experiments received microinjections of $\mathrm{CTb}$ to either
$\mathrm{MDH}$ or PVT. Rats were injected intraperitoneally with $1.3 \mathrm{ml} / \mathrm{kg}$ of the anesthetic ketamine (Ketapex; Apex Laboratories) at a concentration of $100 \mathrm{mg} / \mathrm{ml}$ and with $0.3 \mathrm{ml} / \mathrm{kg}$ of the muscle relaxant xylazine (Rompun; Bayer) at a concentration of $20 \mathrm{mg} / \mathrm{ml}$. Each rat was placed in the stereotaxic apparatus (model 900; David Kopf Instruments), and the flat skull position was achieved by leveling bregma and lambda. A hand drill was used to expose the brain surface and a 30-gauge needle attached to a $1 \mu \mathrm{l}$ Hamilton syringe was lowered into MDH [anterior (A)-posterior $(\mathrm{P})$, -2.9 ; medial (M)-lateral (L), -0.8 ; dorsal (D)-ventral (V), -8.7 ; distances in mm from bregma] or PVT (A-P, $-2.6 ; \mathrm{M}-\mathrm{L},-0.2 ; \mathrm{D}-\mathrm{V},-5.5)$ and $40 \mathrm{nl}$ of $1 \%$ low salt CTb (List Biological Laboratories) was injected using a Quintessential Stereotaxic Injector (catalog \# 53311, Stoelting). Injections were conducted over $2 \mathrm{~min}$ and the needle was left in place for 5 min before removal to allow for diffusion and to reduce spread up the injection tract. Immediately after surgery, rats received intramuscular injections of $0.15 \mathrm{ml}$ of a $300 \mathrm{mg} / \mathrm{ml}$ solution of procaine penicillin and $0.1 \mathrm{ml}$ of $100 \mathrm{mg} / \mathrm{ml}$ cephazolin sodium, and subcutaneous injections of $5 \mathrm{mg} / \mathrm{kg}$ carprofen. Rats were allowed $5 \mathrm{~d}$ to recover from surgery, during which time they were weighed daily.

Cannulae surgery. Before all behavioral testing, rats were either implanted with bilateral guide cannula directed toward $\mathrm{MDH}, \mathrm{LH}$, or a single unilateral guide cannula directed toward PVT. Under identical surgical procedures to the retrograde tracing experiments, bilateral (1.0 $\mathrm{mm}$ center to center) 26 gauge guide cannula (Plastics One) were directed toward MDH (A-P, $-2.8 ; \mathrm{M}-\mathrm{L}, \pm 1.0 ; \mathrm{D}-\mathrm{V},-7.7)$. For $\mathrm{LH}$ we used two 26 gauge guide cannula (Plastics One) directed toward LH [A-P, $-2.3 ; \mathrm{M}-\mathrm{L}, \pm 3.4\left(10^{\circ}\right.$ angle $\left.) ; \mathrm{D}-\mathrm{V},-7.5\right]$. For PVT we used a single 26 gauge guide cannula (Plastics One) directed toward PVT (A-P, $-2.8 ; \mathrm{M}-\mathrm{L}, 1.3$ ( $10^{\circ}$ angle); $\mathrm{D}-\mathrm{V},-4.0$ ]. The guide cannulae were fixed in position with dental cement and anchored with jeweller's screws. A dummy cannula was kept in the guide at all times, except during microinjections.

At the conclusion of the infusion experiments, rats were given an overdose of sodium pentobarbital, and their brains were removed. Unfixed brains were sectioned coronally at $40 \mu \mathrm{m}$ through the hypothalamus. Every third section through the cannula placement was collected on a glass slide and subsequently stained with cresyl violet. Cannula placements were verified at the microscope by the boundaries defined by Paxinos and Watson (1997).

Drugs. Rat CART 55-102 (cocaine- and amphetamine-regulated transcript 55-102) and rat CART 1-27 (Auspep) were dissolved in 0.9\% saline at a concentration of $5.0 \mu \mathrm{g} / \mu \mathrm{l}$. ( \pm )-U50488 hydrochloride [trans-( \pm )3,4-dichloro- $N$-methyl-N-[2-(1-pyrrolidinyl)cyclohexyl] benzeneacetamide hydrochloride] (Tocris Bioscience, catalog \#0495) was dissolved in $0.9 \%$ saline at a concentration of $5.0 \mu \mathrm{g} / \mu \mathrm{l}$.

Infusions. The injection cannulae were connected to $10 \mu$ l Hamilton syringes mounted on an infusion pump. The injection cannulae extended $1 \mathrm{~mm}$ beyond the end of the guide cannula. Drugs (or vehicle) were all infused in a volume of $0.5 \mu \mathrm{l}$ over $2 \mathrm{~min}$, and the injection cannulae left in place for $2 \mathrm{~min}$ after the infusion. For PVT infusions, 1.0 $\mu \mathrm{l}$ was infused over $4 \mathrm{~min}$, and the injection cannulae left in place for 6 min after the infusion.

Immunohistochemistry. Rats in the retrograde tracing experiment were returned to their home cage at the end of the $1 \mathrm{~h}$ test session. Two hours after the beginning of test, rats were deeply anesthetized with sodium pentobarbital ( $100 \mathrm{mg} / \mathrm{kg}$, i.p.) and perfused transcardially with $50 \mathrm{ml}$ of $0.9 \%$ saline, containing $1 \%$ sodium nitrite and heparin (5000 i.u. $/ \mathrm{ml}$ ), followed by $400 \mathrm{ml}$ of $4 \%$ paraformaldehyde in $0.1 \mathrm{M}$ phosphate buffer (PB), $\mathrm{pH}$ 7.4. Brains were postfixed for $1 \mathrm{~h}$ in the same fixative and placed in $20 \%$ sucrose solution overnight. Brains were blocked using a matrix aligned to the atlas of Paxinos and Watson (1997) and $40 \mu \mathrm{m}$ coronal sections were cut using a cryostat (CM 1950, Leica Microsystems). Four serially adjacent sets of sections were obtained from each brain and stored in $0.1 \mathrm{M}$ phosphate buffer saline (PBS) $\mathrm{pH} 7.2$ containing $0.1 \%$ sodium azide.

For immunofluoresence, free-floating sections were washed repeatedly in $0.1 \mathrm{M}$ PBS, pH 7.2, followed by a $2 \mathrm{~h}$ incubation in PBS, $\mathrm{pH} 7.2$, containing 10\% normal horse serum (NHS) and 0.5\% Triton X-100. Sections were then incubated in the primary antibodies diluted in $0.1 \mathrm{M}$ 
PBS, pH 7.2, containing $0.1 \%$ sodium azide, $2 \%$ NHS and $0.2 \%$ Triton $\mathrm{X}-100$, for $48 \mathrm{~h}$ at room temperature, with gentle agitation. The primary antibodies used were goat anti-choleragenoid (1:5000; List Biological Laboratories); guinea pig anti-prodynorphin (1:10,000; Millipore); rabbit anti-c-Fos (1:5000; c-Fos (4), sc-52, Santa Cruz Biotechnology); rabbit anti-orexin (1:20,000; Phoenix Pharmaceuticals). After washing off unbound primary antibodies, sections were then incubated for $4 \mathrm{~h}$ at room temperature in secondary antibodies diluted in $0.1 \mathrm{M}$ PBS, pH 7.2, containing $2 \%$ NHS and $0.2 \%$ Triton X-100 (PBST-X). The secondary antibodies used were donkey anti-sheep FITC (1:500; Jackson ImmunoResearch Laboratories); donkey anti-rabbit Cy3 (1:1000; Jackson ImmunoResearch Laboratories); donkey anti-guinea pig Cy3 (1:2000; Jackson ImmunoResearch Laboratories); donkey anti-guinea pig FITC (1:1000; Jackson ImmunoResearch Laboratories); biotinylated donkey anti-sheep IgG (1:1000; Jackson ImmunoResearch Laboratories). After washing off unbound secondary antibodies sections were mounted onto gelatin-treated slides and coverslipped with buffered glycerol, $\mathrm{pH}$ 8.6. In the triple immunofluoresence experiment, there was an extra $1 \mathrm{~h}$ incubation in PBST-X with AMCA (7-amino-4-methylcoumarin-3-acetic acid)-Avidin (1:100; Vector Laboratories) before coverslipping.

A second series of sections was used to reveal c-Fos in combination with $\mathrm{CTb}$ using two-color peroxidase immunohistochemistry. Freefloating sections were washed repeatedly in $0.1 \mathrm{M} \mathrm{PB}, \mathrm{pH} 7.4$, followed by two 30 min washes in 50\% ethanol, the second of which contained 3\% $\mathrm{H}_{2} \mathrm{O}_{2}$, and were then incubated in 5\% NHS in $\mathrm{PB}, \mathrm{pH}$ 7.4, for $30 \mathrm{~min}$. Sections were incubated in rabbit antiserum against c-Fos (1:5000; c-Fos (4), sc-52, Santa Cruz Biotechnology), which was mixed with goat anticholeragenoid (1:5000; List Biological Laboratories). These primary antibodies were diluted in $0.1 \mathrm{M} \mathrm{PB}, \mathrm{pH} 7.4$, containing $0.1 \%$ sodium azide, $2 \%$ NHS and $0.2 \%$ Triton X-100 (PBT-X), and incubations were for $48 \mathrm{~h}$ at room temperature, with gentle agitation. After washing off unbound primary antibodies, sections were incubated overnight at room temperature in biotinylated donkey anti-rabbit IgG (1:1000; Jackson ImmunoResearch Laboratories) diluted in 2\% NHS PBT-X. After washing off unbound secondary antibody, sections were incubated for $2 \mathrm{~h}$ at room temperature in $\mathrm{ABC}$ reagent (Vector Elite kit: $6 \mu \mathrm{l} / \mathrm{ml}$ avidin and $6 \mu \mathrm{l} / \mathrm{ml}$ biotin; Vector Laboratories). Black immunoreactive (IR) nuclei labeled for c-Fos were revealed by a nickel-intensified diaminobenzidine reaction, with peroxide being generated by glucose oxidase. To do this sections were washed in $\mathrm{PB}$, followed by $0.1 \mathrm{M}$ acetate buffer, $\mathrm{pH}$ 6.0, and then incubated for $15 \mathrm{~min}$ in $0.1 \mathrm{M}$ acetate buffer, $\mathrm{pH} 6.0$, containing $2 \%$ nickel sulfate, $0.025 \%$ 3,3-diaminobenzidine, $0.004 \%$ ammonium chloride, and $0.02 \% \mathrm{D}$-glucose. The peroxidase reaction was started by adding $0.2 \mu \mathrm{l} / \mathrm{ml}$ glucose oxidase and stopped using acetate buffer, $\mathrm{pH}$ 6.0. Brain sections were then washed in $\mathrm{PB}$ and processed again, in a similar manner using biotinylated donkey anti-sheep IgG (1:1000; Jackson ImmunoResearch Laboratories) but without nickel-intensification to localize IR for $\mathrm{CTb}$, revealed as a brown reaction product. Sections were mounted onto gelatin-treated slides, dehydrated, cleared in histolene, and coverslipped with Entellan.

Neuronal counting. Counts of neurons IR for c-Fos and CTb were by an observer unaware of group allocations. The hypothalamus was assessed over six sections beginning at bregma -2.80 . The prefrontal cortex was assessed over six sections beginning at bregma +3.70 . All sections counted were $160 \mu \mathrm{m}$ apart. The dorsomedial hypothalamus was defined as an area that is bordered medially by the third ventricle, and laterally by the mammillothalamic tract. The perifornical hypothalamus is bordered medially by the dorsomedial hypothalamus, and laterally by half a fornix width lateral to the fornix. The lateral hypothalamus is bordered medially by the perifornical hypothalamus, and laterally by the internal capsule.

Data analysis. The numbers of responses were recorded during training, extinction, and test. These data as well as the total counts of c-Fos-IR, $\mathrm{CTb}-\mathrm{IR}$, and c-Fos/CTb double-IR neurons in each brain region were analyzed by means of planned contrasting testing procedure (Harris, 1994). A multivariate approach to repeated measures was adopted which treats each family of within-subject contrasts (i.e., main effects on days, manipulanda, and their associated interaction terms) with their own error terms generating a more powerful analysis of repeated measures data (O'Brien and Kaiser, 1985). The type I error rate $(\alpha)$ was controlled at 0.05 for each contrast tested (Harris, 1994).

\section{Results}

\section{The expression of extinction is associated with activation of ilPFC neurons that project to MDH}

We combined retrograde neuronal tracing from $\mathrm{MDH}$, using cholera toxin B subunit (CTb), with a marker of cellular activation, c-Fos, to identify activation of MDH afferents during test for either extinction or reinstatement. We were interested in determining the activity in afferents to the $\mathrm{MDH}$, which encapsulates the dorsomedial nucleus and medial aspect of perifornical nucleus. This is because PFC projections to $\mathrm{MDH}$ are reported to be primarily from ventral PFC (Thompson and Swanson, 1998; Heidbreder and Groenewegen, 2003). Furthermore we were interested in comparing activation of $\mathrm{MDH}$ afferents during extinction expression and reinstatement to the activation of $\mathrm{LH}$ afferents under these conditions which we reported in our previous studies (Marchant et al., 2009). Before behavioral training, all rats received microinjections of $\mathrm{CTb}$ into $\mathrm{MDH}$. Rats were tested after extinction either for context-induced reinstatement in the original training context $(\mathrm{ABA} ; n=5)$, or for extinction the extinction context $(\mathrm{ABB} ; n=6)$.

\section{Behavior}

In each of the experiments reported here the acquisition of selfadministration and responding during extinction did not differ significantly between groups. The right panel of Figure $1 A$ shows responses during test. For test, there was an overall significant difference in the level of responding between group ABA and $\operatorname{ABB}\left(F_{(1,9)}=7.5 ; p<0.05\right)$. There was an overall significant difference in the level of responding on the active versus inactive nose poke $\left(F_{(1,9)}=18.1 ; p<0.05\right)$. Finally, there was a significant interaction, so that the increase in responding during test in context A was specific to the active nose poke $\left(F_{(1,9)}=9.1 ; p<0.05\right)$. This confirms that alcoholic beer seeking was low when tested in the extinction context $(\mathrm{ABB})$ and significantly higher when tested in the training context (ABA).

\section{Verification of $\mathrm{CTb}$ injection sites}

Figure $1 B$ shows a photomicrograph of a representative $\mathrm{MDH}$ $\mathrm{CTb}$ injection. The spread of CTb deposit was confirmed with immunohistochemistry for $\mathrm{CTb}$ and prodynorphin. Individual $\mathrm{CTb}$ injections are plotted onto the stereotaxic atlas of Paxinos and Watson (1997) in Figure 2. Any rats with CTb injections lateral or dorsal to the fornix, or ventral to the third ventricle, were excluded from analysis.

\section{Distribution of c-Fos-IR in MDH afferents}

Figure $1 C$ shows a representative photomicrograph of IR in ilPFC for c-Fos and CTb. Counts of total CTb-IR, c-Fos-IR and dual-IR neurons were performed throughout PFC. Figure $1 D$ shows the mean ( \pm SEM) total CTb (left), c-Fos (middle), and dual CTb/cFos (right) labeling in ilPFC. There were no differences between groups in total CTb-IR neurons $\left(F_{(1,9)}<1 ; p>0.05\right)$. There was a significant difference between groups in total c-Fos-IR neurons $\left(F_{(1,9)}=6.5 ; p<0.05\right)$. Importantly, there was a significant difference between groups ABA and ABB in total number of neurons dual-IR for $\mathrm{CTb} / \mathrm{c}-\mathrm{Fos}\left(F_{(1,9)}=6.6 ; p<0.05\right)$. This shows significantly greater $\mathrm{c}-\mathrm{Fos} / \mathrm{CTb}$ dual-IR in group $\mathrm{ABB}$ compared with $\mathrm{ABA}$. The same pattern of increased activity in group $\mathrm{ABB}$ was detected when the data were quantified as percentage of CTb-IR cells expressing c-Fos-IR $\left(9.84 \%\right.$ vs $5.36 \% ; F_{(1,9)}=6.2$; 
A
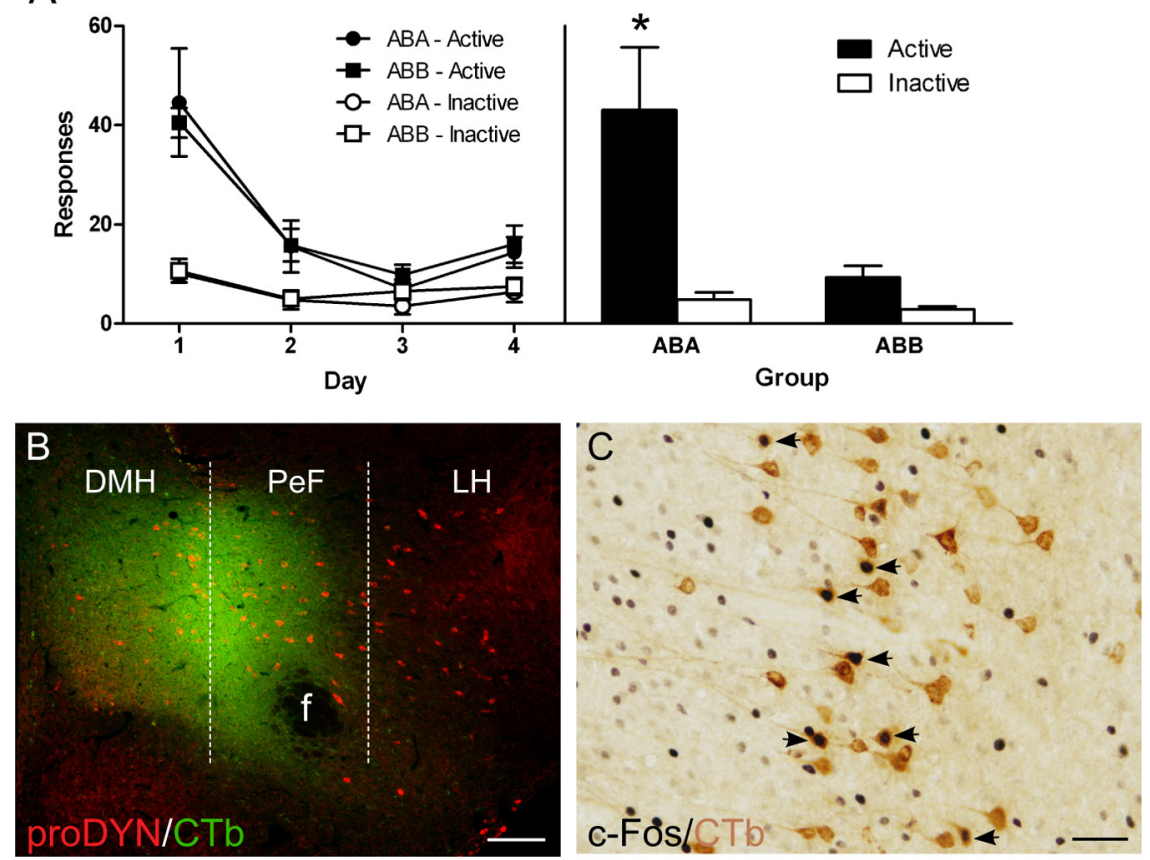

$\mathrm{D}$
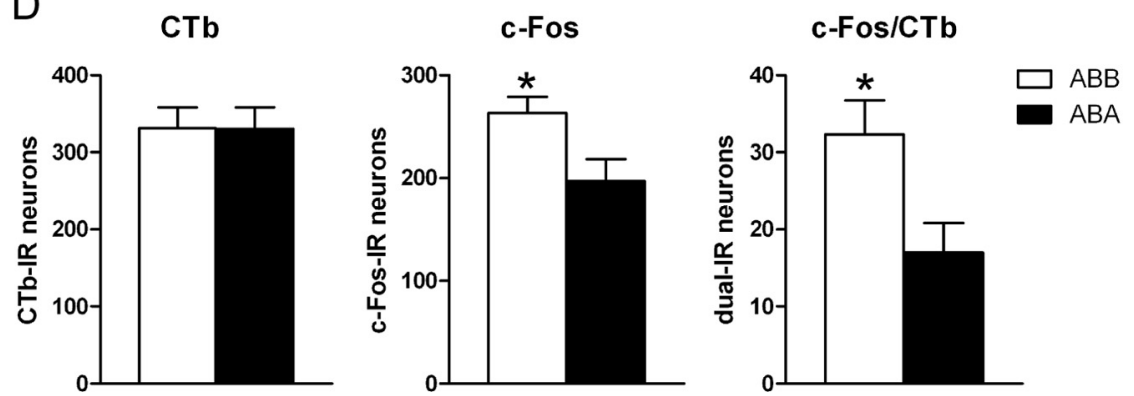

Figure 1. The expression of extinction is associated with activation of ilPFC projections to MDH. $A$, Responses on the active and inactive nose pokes during extinction (left) or test (right). Rats were trained in context $A$, extinguished in context $B$, and then tested in either context $A$ (group $A B A$ ) or context $B(A B B)$. Group $A B B$ showed significantly less responding on test than group $A B A . B$ Representative photomicrograph of an MDH CTb injection. Placements were anatomically verified with dual immunofluoresence for prodynoprhin (red) and (Tb (green). Scale bar, $100 \mu \mathrm{m}$. C, Representative photomicrograph of immunoreactivity (IR) in ilPFC. Arrows point to neurons dual-IR for CTb (brown cell body) and c-Fos (black nuclei). Scale bar, $50 \mu \mathrm{m}$. D, Total counts through ilPFC of neurons (Tb-IR (left), c-Fos-IR (middle), and dual-IR (right). There were no differences between groups in total CTb-IR neurons. Group ABB had higher numbers of total c-Fos-IR neurons than group ABA. Importantly, there was a significant increase in dual-IR in group $A B B$ compared with group $A B A$. Data are expressed as mean ( \pm SEM). ${ }^{*} p<0.05$ comparing group $A B B$ to ABA.

$p<0.05)$ or as percentage of c-Fos-IR cells expressing CTb-IR $\left(12.09 \%\right.$ vs $\left.8.17 \% ; F_{(1,9)}=6.1 ; p<0.05\right)$.

These effects were specific to ilPFC and were not observed in other afferents to MDH. For example, in plPFC, there were no differences between groups in either total CTb-IR neurons $\left(F_{(1,9)}=1.9\right.$; $p>0.05)$, total c-Fos-IR neurons $\left(F_{(1,9)}<1 ; p>0.05\right)$, or dual CTb-IR/c-Fos-IR neurons $\left(F_{(1,9)}=2.5 ; p>0.05\right)$. Likewise, although PVT contained robust retrograde labeling, there were no differences between groups in dual CTb-IR/c-Fos-IR labeling.

\section{MDH inhibition via CART 55-102 prevents expression of extinction}

The previous experiment indicates that an ilPFC $\rightarrow \mathrm{MDH}$ pathway is recruited during the expression of extinction of alcoholic beer seeking. ilPFC is critical for expression of extinction because reversible inactivation prevents expression of extinction of cocaine seeking (Peters et al., 2008). If MDH is likewise important for inhibiting responding during extinction expression then pharmacological manipulations of $\mathrm{MDH}$ should also prevent the expression of extinction. The next experiment tested this possibility by pharmacological manipulations of MDH before a test of extinction expression.

In our initial pilot experiments we studied the effects of infusions of the $\mathrm{GABA}_{\mathrm{A}}$ and $\mathrm{GABA}_{\mathrm{B}}$ receptor agonists muscimol and baclofen into MDH on expression of extinction. However, these infusions produce somnolesence, markedly reduced behavior, and suppressed responding on both the active and inactive nose poke during test in the extinction context as well as the training context rendering interpretation difficult. Similar effects were obtained with MDH infusions of muscimol alone. Therefore we used microinjection of the inhibitory neuropeptide cocaine and amphetamine-regulated transcript (CART) to provide more selective inhibition of $\mathrm{MDH}$. The CART receptor has not been cloned, however the CART 55-102 neuropeptide causes inhibitory postsynaptic actions via a $\mathrm{G}_{\mathrm{i} / \mathrm{o}}$ containing G-protein-coupled receptor (Rogge et al., 2008). Importantly, MDH infusions of CART 55-102 prevent inhibition of motivated behavior, for example increasing feeding in sated rats (Abbott et al., 2001), and CART 55-102 reduces c-Fos expression in hypothalamic orexin neurons (Pirnik et al., 2010). Finally, we detected the expression of CART immunoreactivity in $\mathrm{MDH}$ and found that CART terminals are closely associated with prodynorphin/orexin neurons in MDH (Fig. $3 A, B)$. This suggests that CART has a functional role in $\mathrm{MDH}$, and allows us to use CART as a more selective inhibitor of MDH neurons. Therefore we tested whether MDH infusions of CART 55-102 would prevent expression of extinction.

Rats were implanted with bilateral cannulae targeting $\mathrm{MDH}$. They were then trained to respond for $4 \%$ alcoholic beer in context A before extinction training in context $\mathrm{B}$. All rats were then tested in context B following infusion of CART 55-102 $(n=7)$, vehicle $(n=5)$, CART 1-27 $(n=5)$. An additional group of rats was implanted with cannulae targeting $\mathrm{LH}$. These rats were trained identically to the other rats, and were tested in context $\mathrm{B}$ after LH infusion of CART 55-102 $(n=7)$.

The left panel of Figure $3 C$ shows responses during the last day of extinction and test. MDH infusions of CART 55-102 on test significantly increased responding on the active nose poke compared with vehicle $\left(F_{(1,10)}=12.2 ; p<0.05\right)$ but there were no differences between groups in responding on the inactive nose poke $\left(F_{(1,10)}=3.1, p>0.05\right)$. This finding shows that $\mathrm{MDH}$ infusion of CART 55-102 prevents the expression of extinction.

A series of control conditions assessed the pharmacological and anatomical specificity of this effect. The CART propeptide produces a 27 aa $\mathrm{N}$-terminal hydrophobic signal sequence (Stein 


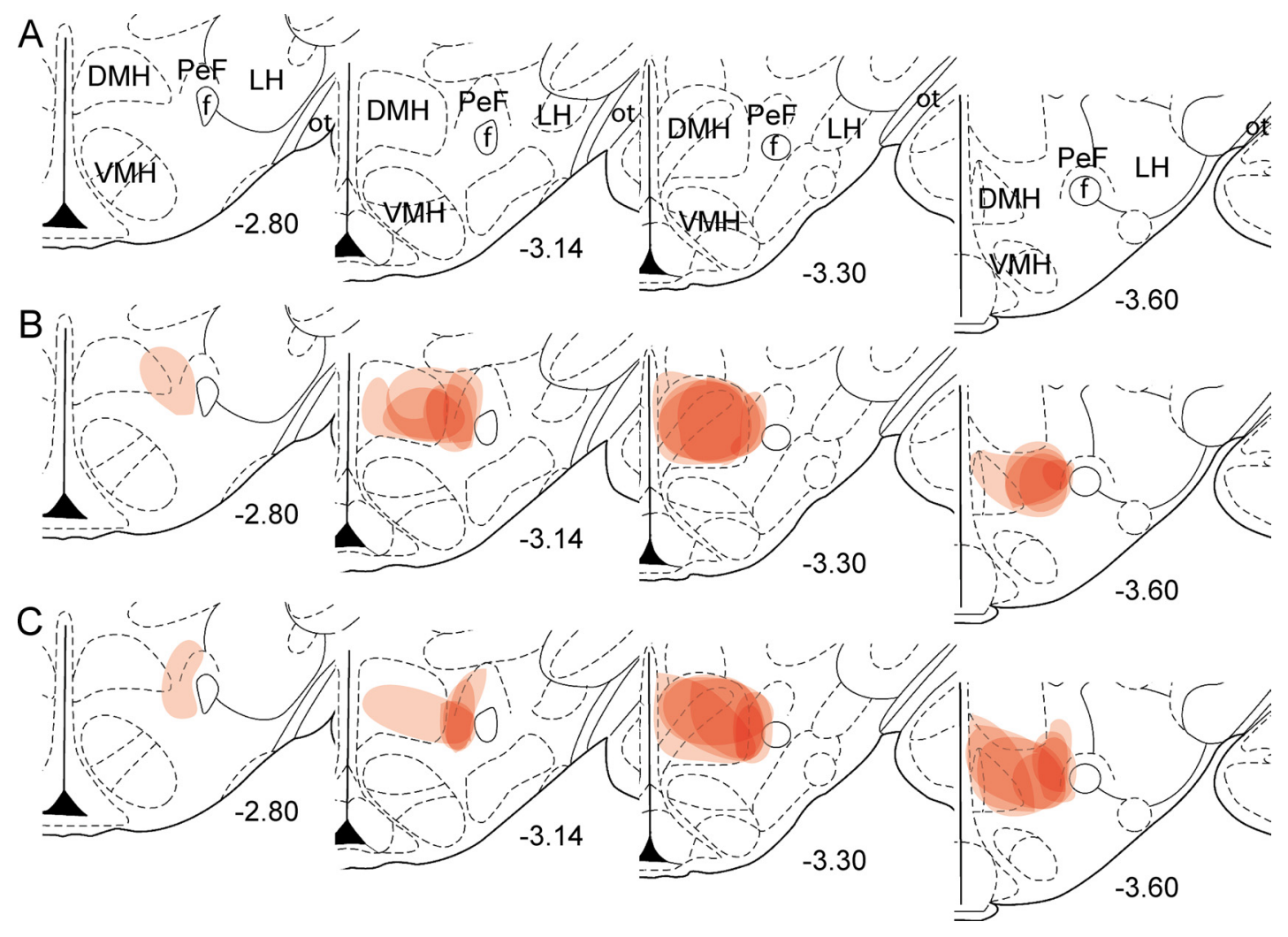

Figure 2. Schematic drawings through hypothalamus of the location of (Tb injections in MDH. A, Four different stereotaxic levels adapted from Paxinos and Watson (1997) where correct CTb injections were confirmed with immunohistochemistry. $\boldsymbol{B}, \boldsymbol{C}$, Individual cases from group ABA $(\boldsymbol{B})$ and group $A B B(\boldsymbol{C})$ are plotted through the four levels. Numbers represent $\mathrm{mm}$ from bregma. Each injection is plotted at $25 \%$ opacity so that overlap of injection sites is apparent with increased color intensity. $\mathrm{f}$, fornix; ot, optic tract; VMH, ventromedial hypothalamus.

et al., 2006) (CART 1-27), known to be inactive in most preparations. Infusions of CART 1-27 resulted in no difference in responding compared with vehicle on the active $\left(F_{(1,10)}=2.7 ; p>\right.$ $0.05)$ or inactive nose poke $\left(F_{(1,10)}<1 ; p>0.05\right)$. To test for anatomical specificity, we infused CART 55-102 into LH. Compared with $\mathrm{MDH}$ vehicle, there was no difference in active $\left(F_{(1,10)}=\right.$ $1.2, p>0.05)$ or inactive $\left(F_{(1,10)}=1.6 ; p>0.05\right)$ nose pokes after LH infusions of CART 55-102.

An additional experiment using a 10\% sucrose reinforcer was completed to determine whether this effect was specific to reinstatement of extinguished alcoholic beer seeking. Rats were implanted with bilateral cannulae targeting $\mathrm{MDH}$. They were then trained to respond for $10 \%$ sucrose in context A before extinction training in context B. All rats were then tested in context B following infusion of CART 55-102 $(n=6)$ or vehicle $(n=6)$.

The right panel of Figure $3 C$ shows responses during the last day of extinction and test. MDH infusions of CART 55-102 significantly increased responding on the active nose poke compared with vehicle $\left(F_{(1,10)}=7.85 ; p<0.05\right)$. Responding on the inactive nose poke was not significantly different after $\mathrm{MDH}$ infusions of CART 55-102 compared with vehicle $\left(F_{(1,10)}=4.8 ; p>\right.$ $0.05)$. It is worth noting that the apparent increase in inactive nose pokes was due entirely to the results of two rats who received MDH infusions of CART 55-102.

\section{CART 55-102 effects are specific to expression of extinction}

It is possible that CART 55-102 prevented the expression of extinction because it increased motivation to respond or increased responding due to other nonspecific effects. If so, then CART 55-102 should also increase nose poke responding under other conditions. To further assess the behavioral specificity of the ef- fects of CART 55-102, we tested whether it was dependent on the expression of extinction. In two experiments, we tested the effect of $\mathrm{MDH}$ infusions of CART 55-102 in rats with no selfadministration training, in rats tested for context-induced reinstatement and in rats during self-administration.

In the untrained experiment, rats received no selfadministration training, but received $4 \mathrm{~d}$ of context exposure under the same conditions as extinction for the previous experiments. Over the next $2 \mathrm{~d}$, rats $(n=6)$ were tested in the same context after MDH infusions of either CART 55-102 or saline. Rats were tested after both infusions with infusion order counterbalanced. In the context-induced reinstatement experiment, rats were trained and extinguished in a manner identical to the previous experiments, but received $\mathrm{MDH}$ infusions of either CART 55-102 $(n=5)$ or vehicle $(n=7)$ before test for responding in context $\mathrm{A}$.

The left panel of Figure $3 D$ shows the mean $( \pm$ SEM) responses during test in untrained rats. There were no differences in responding between nose pokes $\left(F_{(1,5)}=2.6 ; p>0.05\right)$, between infusion type $\left(F_{(1,5)}<1 ; p>0.05\right)$, nor was there a manipulanda $\times$ infusion type interaction $\left(F_{(1,5)}=1.7, p>0.05\right)$. This shows that MDH infusions of CART 55-102 do not simply increase nose-poke behavior.

The right panel of Figure $3 D$ shows the mean ( \pm SEM) responses on the last day of extinction and during test for rats tested for context-induced reinstatement. There was evidence for context-induced reinstatement because there was more responding during test in the training context than at the end of extinction training $\left(F_{(1,10)}=59.7, p<0.05\right)$ and this increase was significantly greater for the active than inactive nose poke $\left(F_{(1,10)}=\right.$ $36.5, p<0.05)$. There was no overall difference between groups 


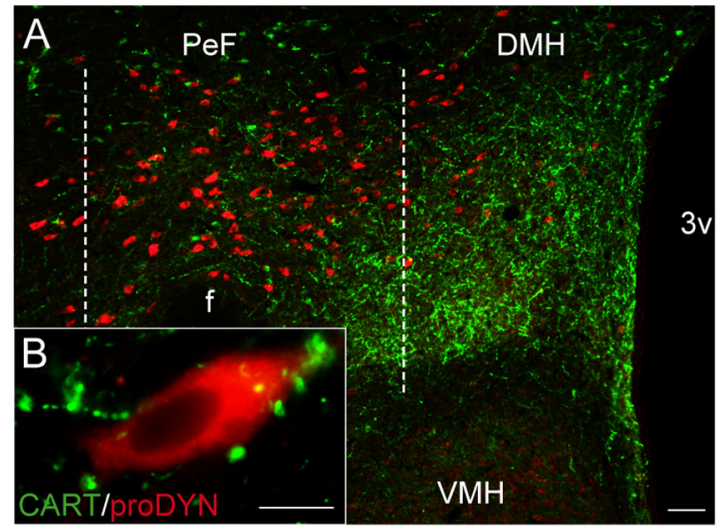

C Alcoholic Beer

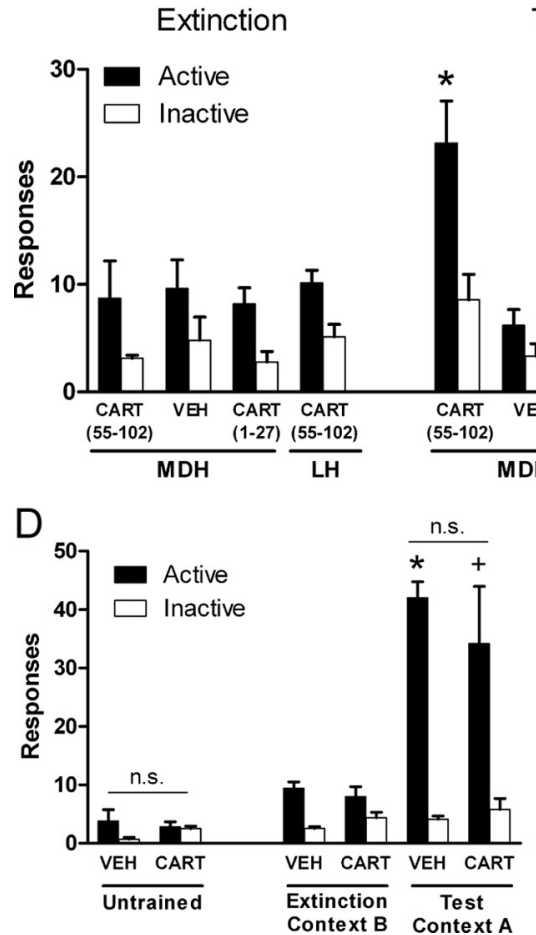

Test

Extinction

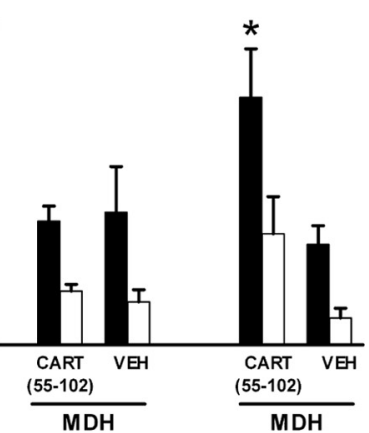

E

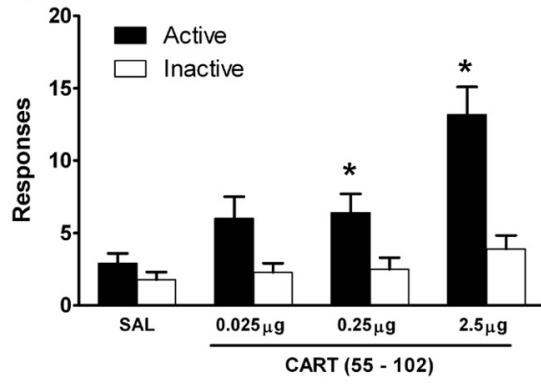

Figure 3. MDH infusion of CART 55-102 reinstates both extinguished alcoholic beer and sucrose seeking in the extinction context. $A$, Low-magnification photomicrograph of MDH showing dense CART terminals and prodynorphin neurons. Scale bar, $100 \mu \mathrm{m} . \boldsymbol{B}$, Photomicrograph of a single prodynorphin neuron showing close associations of CART terminals. Scale bar, $10 \mu \mathrm{m}$. $C$, The left panel shows mean ( \pm SEM) responses on the active and inactive nose poke during the last day of extinction and on test for rats trained to respond for $4 \%$ alcoholic beer. MDH infusions of CART 55-102 selectively increased responding on the active, but not inactive, nose poke compared with vehicle (VEH). There was no difference in responding between MDH vehicle and either MDH CART 1-27, or LH CART 55-102. The right panel shows responses for rats trained to respond for $10 \%$ sucrose. MDH infusion of CART 55-102 selectively increased responding on the active nose poke compared with vehicle. ${ }^{*} p<0.05$ MDH CART 55-102 vs MDH VEH active nose poke. D, CART-induced reinstatement is dependent on the expression of extinction (Ext). The left panel shows responses on the active and inactive nose pokes on test after MDH infusions of either CART 55-102 or vehicle in rats that did not receive self-administration training. CART 55-102 had no effect in untrained animals. The right panel shows responses on the active and inactive nose pokes on the last day of extinction and during test. There were no differences between groups indicating that MDH infusions of CART 55-102 have no effect on ABA context-induced reinstatement. ${ }^{*} p<0.05$ VEH Ext vs Test. $+p<0.05$ CART Ext vs Test. $E$, CART-induced reinstatement of extinguished alcoholic beer seeking is dose-dependent. Mean ( \pm SEM) responses on the active and inactive nose pokes during test after MDH infusions of $0,0.025,0.25$, and $2.5 \mu \mathrm{g}$ of CART 55-102. CART 55-102 infusions into MDH dose-dependently increased responding on the active nose poke. ${ }^{*} p<0.05$. 3v, third ventricle; f, fornix; VMH, ventromedial hypothalamus.

on test $\left(F_{(1,10)}<1 ; p>0.05\right)$, however there was significantly more responding on the active than inactive nose poke $\left(F_{(1,10)}=50.1 ; p<0.05\right)$. Importantly, there was no group $\times$ manipulanda interaction on test $\left(F_{(1,10)}=1.0 ; p>0.05\right)$,
Sucrose

Test

indicating that $\mathrm{MDH}$ infusions of CART 55-102 had no effect on contextinduced reinstatement.

Finally, these rats were retrained to self-administer $4 \%$ alcoholic beer in context A. Rats were first retrained for $1 \mathrm{~d}$ in context A on the FR1 schedule to reestablish nose- poking behavior in the absence of any MDH infusion. There was no difference between groups during this retraining $\left(F_{(1,10)}<1 ; p>0.05\right)$. The next day rats were returned to context A for a selfadministration test after $\mathrm{MDH}$ infusions of CART 55-102 or vehicle. There were no differences between groups during this test session (mean \pm SEM responses: CART 55-102 = 72.0 \pm 10.6 ; vehicle $=58.3 \pm 6.9)\left(F_{(1,10)}<1 ; p>\right.$ 0.05).

Together, these results show that MDH infusions of CART 55-102 do not increase nose-poking behavior, have no effect on responding in the training context, and have no effect on self-administration suggesting that the effects of MDH CART 55-102 infusions are specific to being tested in the extinction context.

\section{CART 55-102 dose-response function}

To assess the pharmacological specificity of the CART prevention of extinction, we constructed a dose-response function for CART 55-102 effects on extinction expression. Rats were trained to respond for $4 \%$ alcoholic beer in context A before extinction in context B. Rats $(n=10)$ were tested four times: after $\mathrm{MDH}$ infusions of $0 \mu \mathrm{g}, 0.025 \mu \mathrm{g}, 0.25 \mu \mathrm{g}$, and $2.5 \mu \mathrm{g}$ of CART 55-102. The dose order was fully counterbalanced. Test sessions were $48 \mathrm{~h}$ apart and there was an additional extinction session on the day between each test.

Figure $3 E$ shows responding during test. For test, there was a significant main effect of nose poke $\left(F_{(1,9)}=82.4 ; p<\right.$ $0.05)$ and linear effect of dose $\left(F_{(1,9)}=\right.$ $17.4 ; p<0.05)$. Importantly, there was a significant manipulanda $\times$ dose interaction so that the increase in responding caused by increasing concentration of CART 55-102 was specific to the active nose poke $\left(F_{(1,9)}=17.5 ; p<0.05\right)$. Individual comparisons revealed manipulanda $\times$ dose interactions for vehicle compared with $0.25 \mu \mathrm{g}\left(F_{(1,9)}=12.7 ; p<\right.$ $0.05)$ and $2.5 \mu \mathrm{g}$ of CART $55-102\left(F_{(1,9)}=\right.$ $19.8 ; p<0.05)$. This shows that CART 55-102 dose-dependently increases responding on the active nose poke. The magnitude of this effect was smaller in than the previous experiments. However, this experiment involved repeated testing (four tests), with noninfusion extinction days 
between each test, for the effects of CART 55-102 on extinction expression. This repeated testing will reduce overall levels of responding.

\section{The expression of extinction is associated with activation of $\mathrm{MDH}$ neurons that project to PVT}

Our findings suggest that MDH may serve a key role in inhibiting alcoholic beer seeking during extinction expression. If this is the case, then an MDH efferent pathway should also be recruited during extinction expression. MDH projects extensively to paraventricular thalamus (PVT). PVT is a key structure in the neural network controlling reinstatement of drug and reward seeking (Dayas et al., 2008; Hamlin et al., 2009). Hypothalamic control of PVT therefore has the potential to regulate the balance between abstinence (extinction) and relapse (reinstatement). We determined the pattern of c-Fos expression in hypothalamic neurons that project to PVT during tests for extinction and reinstatement. All rats received injections of CTb into PVT and were trained to respond for $4 \%$ alcoholic beer in context A, and extinguished in context B. Rats were then tested either for context-induced reinstatement in the original training context (ABA; $n=8$ ) or for extinction expression in the extinction context $\mathrm{B}(\mathrm{ABB} ; n=6)$.

\section{Behavior}

Figure $4 A$ shows the mean $( \pm S E M)$ responding during extinction training and test. For test, there was an overall significant difference in level of responding between group $\mathrm{ABA}$ and group $\mathrm{ABB}$ $\left(F_{(1,12)}=9.1 ; p=0.011\right)$. There was also an overall significant difference in responding on the active versus inactive nose poke $\left(F_{(1,12)}=28.1 ; p<0.001\right)$. Finally, there was a significant interaction, so that the increase in responding during test in context A was specific for the active nose poke $\left(F_{(1,12)}=13.3, p=\right.$ $0.003)$. This confirms that responding was significantly lower when tested in the extinction $(\mathrm{ABB})$ versus the training context (ABA).

\section{Verification of PVT injection sites}

Figure $4 B$ shows a representative photomicrograph of a CTb injection into PVT. The spread of CTb deposit was confirmed with immunohistochemistry for CTb and orexin, because orexin terminal staining delineates the borders of PVT (Kirouac et al., 2005; Li and Kirouac, 2008). Individual CTb injections are plotted onto the stereotaxic atlas of Paxinos and Watson (1997) in Figure 5. Injections that were $>50 \%$ outside of orexin terminal
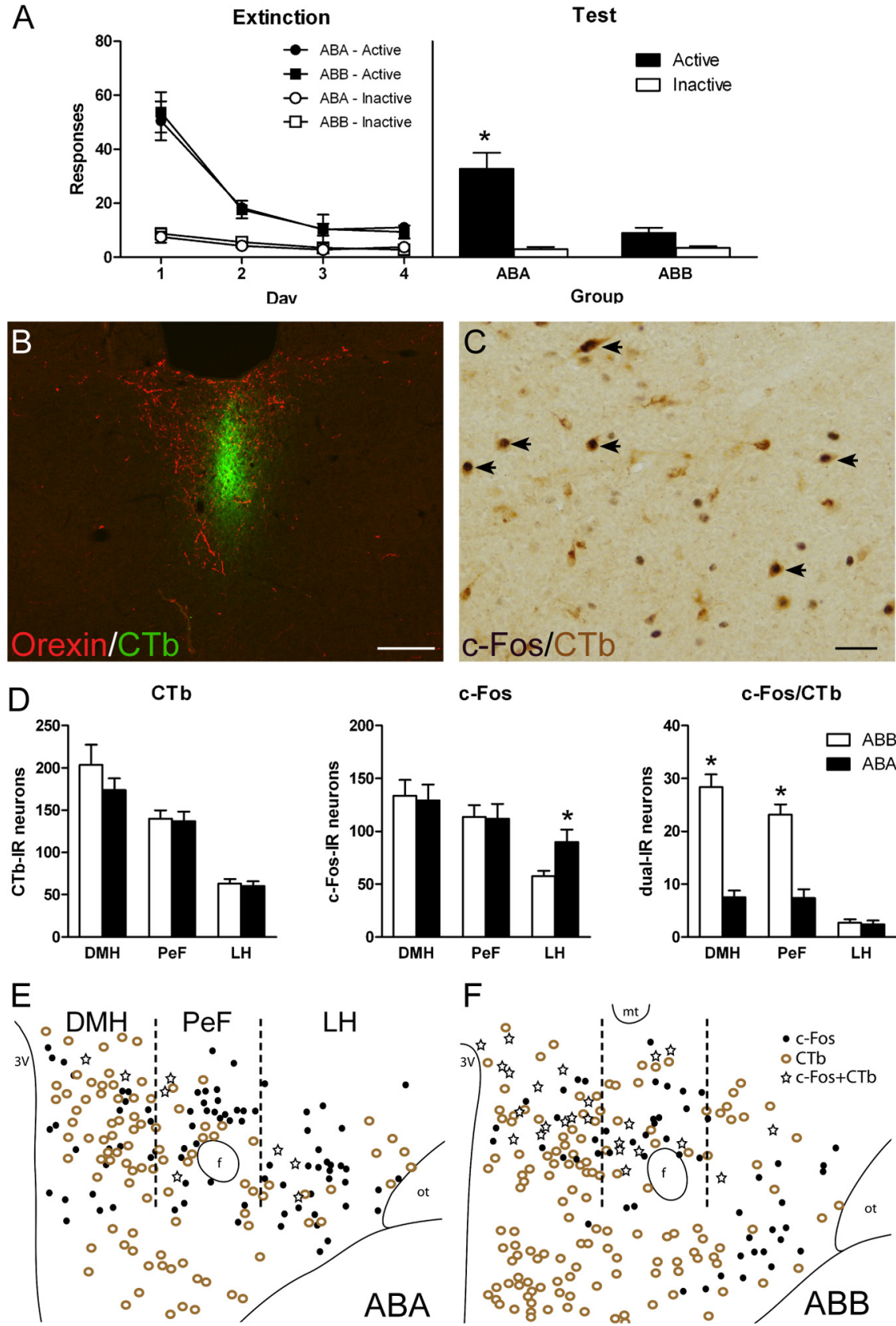

Figure 4. The expression of extinction is associated with activation of MDH projections to PVT. $\boldsymbol{A}$, Responses on active and inactive nose pokes during extinction (left) or test (right). Rats were trained in context $A$, extinguished in context $B$, and then tested in either context $A$ (group $A B A$ ) or context $B(A B B)$. Group $A B B$ showed significantly less responding on test than group $A B A$. $B$, Representative photomicrograph of PVT CTb injection. Placements were verified with dual immunofluoresence for orexin (red) and CTb (green). Scale bar, $100 \mu \mathrm{m}$. C, Representative photomicrograph of immunoreactivity in MDH. Arrows point to neurons dual-IR for CTb and c-Fos. Scale bar, $50 \mu \mathrm{m}$. D, Total counts through dorsal hypothalamus of CTb-IR (left), c-Fos-IR (middle), and dual-IR (right). There was no difference between groups in total CTb-IR neurons in DMH, PeF, or LH. There was no difference between groups in total c-Fos-IR in DMH and PeF. Group ABA showed significantly more total c-Fos-IR in LH compared with group ABB. In both DMH and PeF there was significantly more dual-IR neurons in group $A B B$ compared with group $A B A$. There were no differences between groups in $\mathrm{LH}$. $\boldsymbol{E}, \boldsymbol{F}$, Representative plots of CTb-IR, C-Fos-IR, and dual-IR distribution throughout dorsal hypothalamus in group $A B A(\boldsymbol{E})$ and $A B B(\boldsymbol{F})$. Data are expressed as mean ( $\pm S E M) .{ }^{*} p<0.05$ comparing group $A B B$ to $A B A . f$, fornix; $m t$, mammillothalamic tract; ot, optic tract.

labeling, or were too large, were excluded from all analyses. The pattern of retrograde labeling in the hypothalamus was similar to that seen in the literature with CTb-IR in lateral hypothalamus (LH), perifornical hypothalamus $(\mathrm{PeF})$ and dorsomedial hypothalamus (DMH) (Kirouac et al., 2005, 2006). 

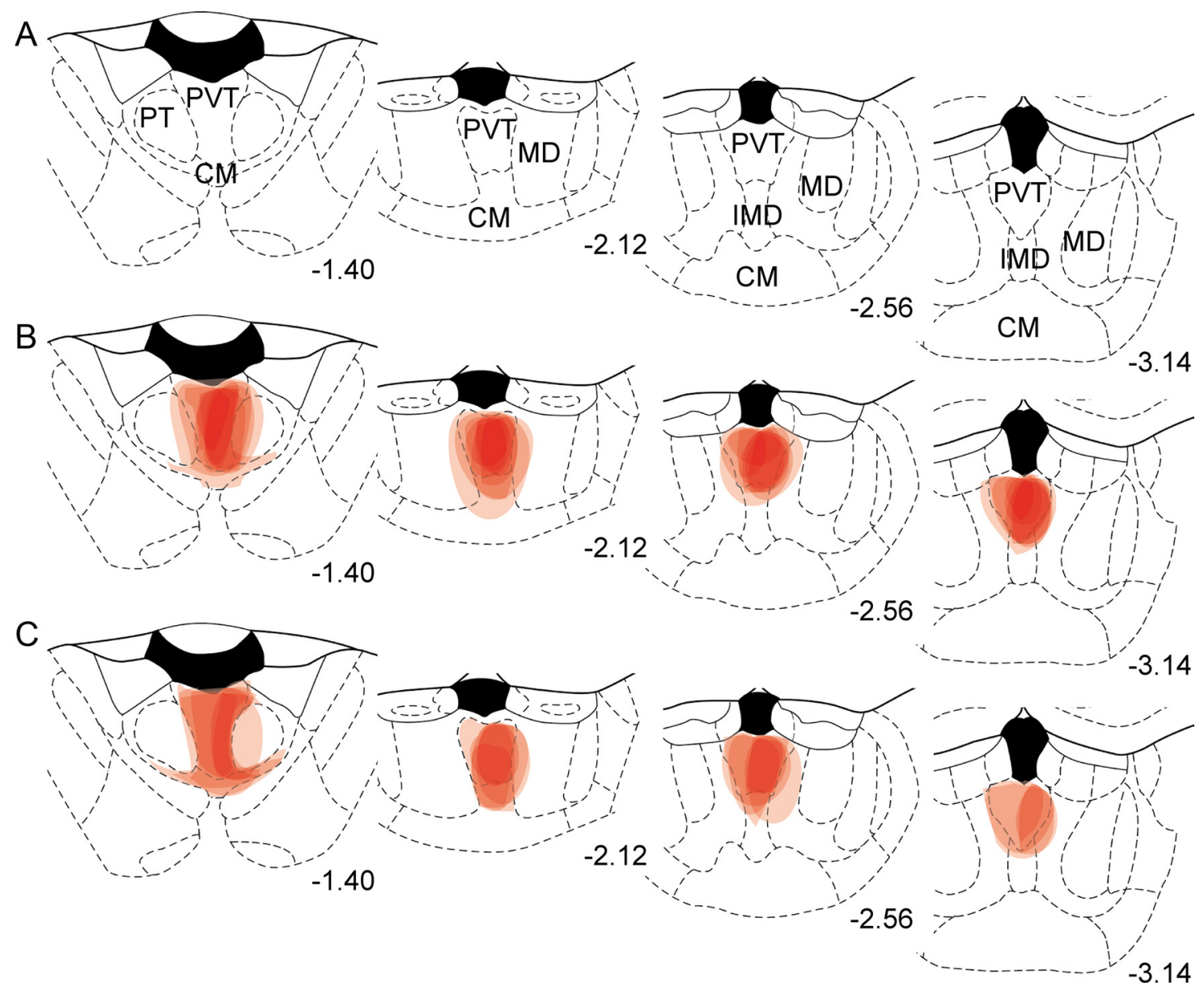

Figure 5. Schematic drawings through thalamus of the location of CTb injections in PVT. A, Four different stereotaxic levels adapted from Paxinos and Watson (1997) where correct CTb injections were confirmed with immunohistochemistry. $\boldsymbol{B}, \boldsymbol{C}$, Individual cases from group $A B A(B)$ and group $A B B(C)$ are plotted through the four levels. Numbers represent $m m$ from bregma. Each injection is plotted at $25 \%$ opacity so that overlap of injection sites is apparent with increased color intensity. CM, central medial thalamic nucleus; IMD, intermediodorsal thalamic nucleus; MD, mediodorsal thalamic nucleus; PT, paratenial thalamic nucleus.

Table 1. Mean and SEM (in parentheses) number of neurons dual-IR for c-Fos/CTb (count), percentages of c-Fos-IR neurons expressing CTb-IR (\% c-Fos), and percentages of CTb-IR neurons expressing c-Fos-IR (\% CTb) after CTb injection into PVT

\begin{tabular}{|c|c|c|c|c|c|c|}
\hline & Count & & $\%$ c-Fos & & $\%$ CTb & \\
\hline & $A B A$ & $A B B$ & $A B A$ & $A B B$ & $A B A$ & $A B B$ \\
\hline DMH & $7.5(0.9)$ & $28.3^{*}(2.05)$ & $5.8(0.6)$ & $22.4^{*}(2.5)$ & $4.4(0.5)$ & $14.3^{*}(0.9)$ \\
\hline $\mathrm{PeF}$ & $7.4(1.7)$ & $23.2^{*}(1.7)$ & $7.9(3.0)$ & $20.7^{*}(1.0)$ & $5.2(1.2)$ & $16.9^{*}(1.3)$ \\
\hline LH & $2.4(0.6)$ & $2.7(0.6)$ & $3.0(0.9)$ & $4.7(0.9)$ & $4.0(0.9)$ & $4.1(0.9)$ \\
\hline
\end{tabular}

${ }^{*} A B B>A B A, p<0.05$.

Distribution of c-Fos-IR in hypothalamic afferents to PVT

Figure $4 C$ shows a representative photomicrograph of IR in hypothalamus for c-Fos and CTb. Figure $4 D$ shows the mean ( \pm SEM) totals of CTb-IR (left), c-Fos-IR (middle), and dual-IR (right) in DMH, PeF, and LH. Figure 4, E and $F$, shows plots of the distribution of $\mathrm{CTb}$, c-Fos, and double labeled neurons in representative sections through the hypothalamus in rats tested either for context-induced reinstatement (4E) or extinction (4F).

There were no differences between groups in total numbers of CTb-IR cells in DMH $\left(F_{(1,12)}=1.3 ; p>0.05\right), \operatorname{PeF}\left(F_{(1,12)}<1\right.$; $p>0.05)$, or LH $\left(F_{(1,12)}<1 ; p>0.05\right)$. There were no differences between groups in total c-Fos-IR in DMH and $\mathrm{PeF}\left(F_{(1,12)}<1\right.$; $p>0.05)$. In LH, there was a significant increase in total c-Fos-IR in group $\mathrm{ABA}$ compared with group $\mathrm{ABB}\left(F_{(1,12)}=5.1 ; p<0.05\right)$ (Hamlin et al., 2007). For dual-IR neurons, there was signifi- cantly greater $\mathrm{c}-\mathrm{Fos} / \mathrm{CTb}$ in group $\mathrm{ABB}$ compared with $\mathrm{ABA}$ in $\operatorname{DMH}\left(F_{(1,12)}=66.8 ; p<0.05\right)$ and $\operatorname{PeF}\left(F_{(1,12)}=37.9 ; p<0.05\right)$. This difference was not found in $\operatorname{LH}\left(F_{(1,12)}<1 ; p>0.05\right)$. The same pattern of increased dual labeling in group $\mathrm{ABB}$ in $\mathrm{DMH}$ and $\mathrm{PeF}$, but not $\mathrm{LH}$, was detected regardless of whether the data were quantified as percentage of CTb-IR cells expressing c-Fos-IR or as percentage of c-Fos-IR cells expressing CTb-IR (Table 1). This shows that an $\mathrm{MDH} \rightarrow$ PVT pathway is recruited during expression of extinction of alcoholic beer seeking.

The majority of MDH to PVT extinction neurons express the opioid propeptide prodynorphin

To determine the phenotype of MDH efferents to PVT activated during extinction expression we used triple-label immunofluoresence. Rats received injections of CTb into PVT before behav- 
ioral training. Rats were tested for contextinduced reinstatement ( $\mathrm{ABA} ; n=5)$ or for extinction expression (ABB; $n=5)$. Brain sections were then processed for three-color immunofluoresence detecting IR for CTb, c-Fos, and prodynorphin.

\section{Behavior}

Figure $6 \mathrm{~A}$ shows responding during extinction training and test. For test, the overall difference in the level of responding between groups approached significance $\left(F_{(1,8)}=5.2 ; p=0.052\right)$. There was an overall significant difference in the level of responding on the active versus inactive nose poke $\left(F_{(1,8)}=20.1 ; p<\right.$ $0.05)$. Importantly, there was a significant interaction, so that the increase in responding during test in context A was specific to the active nose poke $\left(F_{(1,8)}=7.1\right.$; $p<0.05)$.

\section{Verification of PVT injection sites}

The spread of CTb deposit was confirmed in the same manner as the previous experiment. Individual $\mathrm{CTb}$ injections are plotted onto the stereotaxic atlas of Paxinos and Watson (1997) in Figure 7. The pattern of retrograde labeling in hypothalamus was similar to the previous experiment.

Expression of prodynorphin-IR in PVT projecting extinction neurons

The distribution of $\mathrm{CTb} / \mathrm{c}$-Fos-IR neurons was similar to the previous experiment. There were similar numbers of $\mathrm{CTb} / \mathrm{c}$-Fos-IR neurons in both DMH and PeF. So we performed total counts of $\mathrm{CTb} / \mathrm{c}-$ Fos-IR and CTb/c-Fos/prodynorphin-IR neurons throughout the $\mathrm{MDH}$. Figure $6 B$ shows a low-power photomicrograph of the distribution of neurons triple-IR for CTb, c-Fos, and prodynorphin. Figure $6 C$ shows a highpower photomicrograph of an example triple-IR neuron. Figure $6 D$ shows the mean $( \pm$ SEM) total number of neurons. Replicating the previous experiment, there were significantly more neurons in $\mathrm{MDH}$ dual-IR for CTb and c-Fos in rats tested for extinction compared with context-induced reinstatement $\left(F_{(1,8)}=\right.$ $30.5 ; p<0.05)$. The mean percentage of neurons that were dual-IR for CTb and c-Fos that were also IR for prodynorphin in rats tested for extinction (group $\mathrm{ABB}$ ) was 57.3 $( \pm 4.01)$. A similar percentage was found in rats tested in the training context (group ABA) $(53.7 \% \pm 7.50)$. However, there were significantly more neurons triple-IR for c-Fos/CTb/prodynorphin in group $\mathrm{ABB}$ tested for extinction than group ABA tested for reinstatement $\left(F_{(1,8)}=13.0 ; p<0.05\right)$. This shows that expression of extinction is associated with increased activation of $\mathrm{MDH}$ prodynorphin neurons projecting to PVT.

E
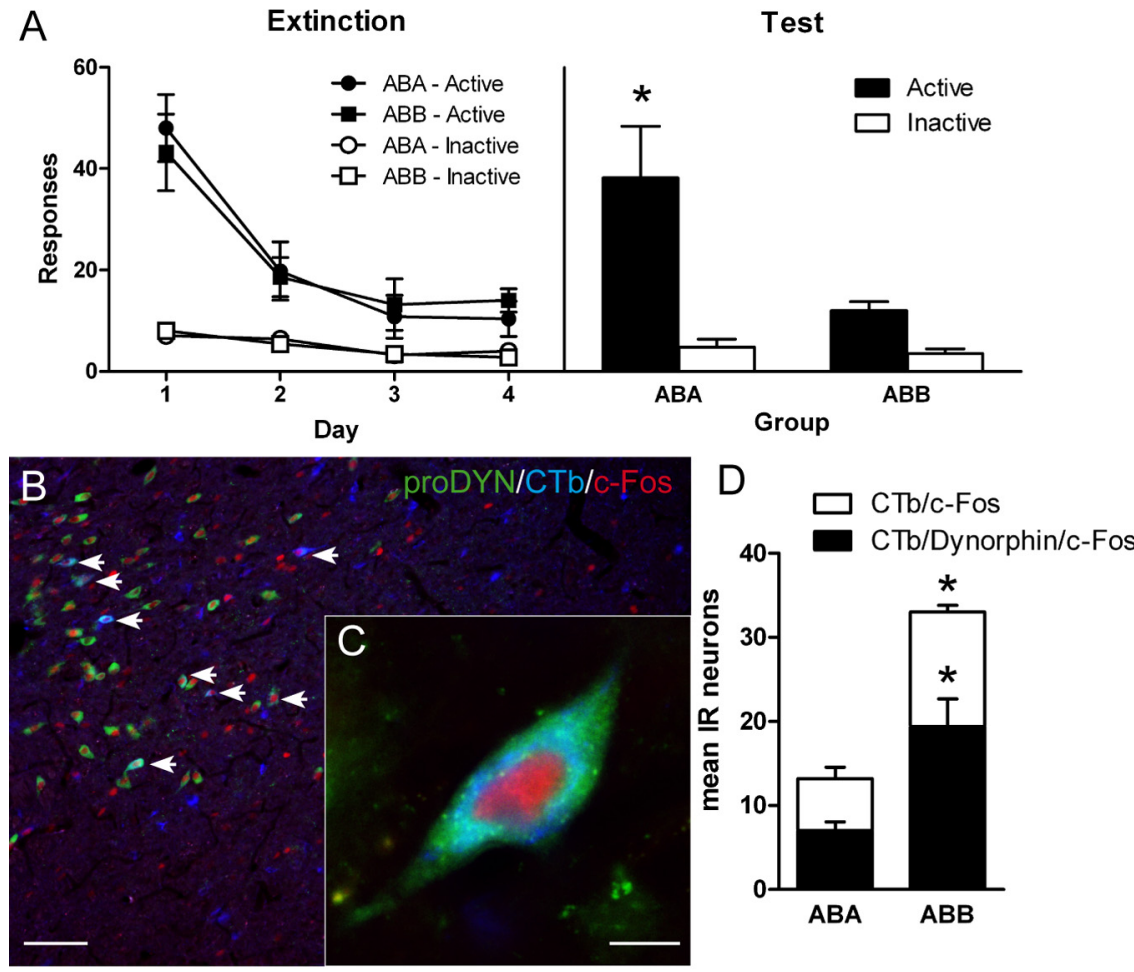

Extinction

Test

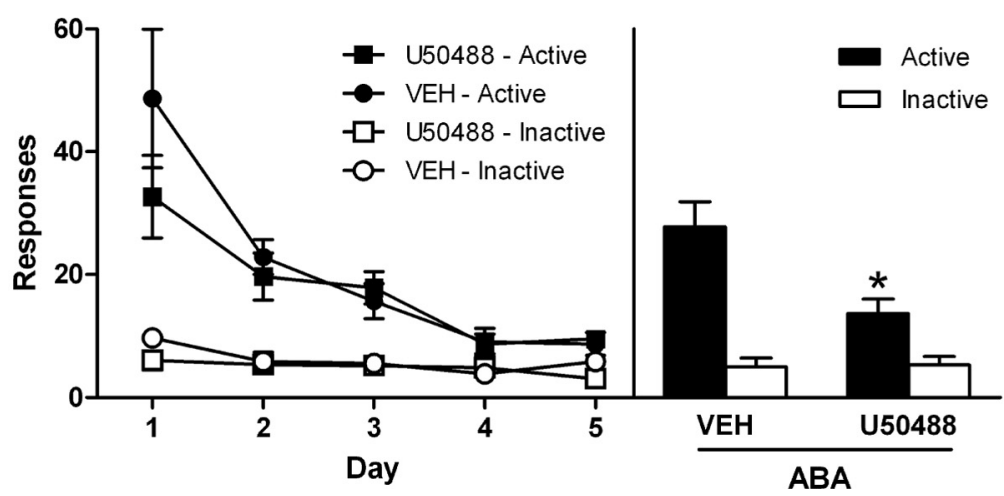

Figure 6. MDH extinction neurons express the opioid propeptide prodynorphin, and activation of $\kappa$ opioid receptors in PVT is sufficient to inhibit context-induced reinstatement of alcoholic beer seeking. $A$, Responses on active and inactive nose pokes during extinction (left) or test (right). Rats were trained in context $A$, extinguished in context $B$, and then tested in either context $A$ (group $A B A$ ) or context $B(A B B)$. Group $A B B$ showed significantly less responding on test than group $A B A$. $B$, Low-magnification photomicrograph of $\mathrm{MDH}$, arrows point to neurons triple-IR for prodynorphin/CTb/c-Fos. Scale bar, $100 \mu \mathrm{m}$. C, Photomicrograph of a single neuron triple-IR for prodynorphin/CTb/c-Fos. Scale bar, $10 \mu \mathrm{m}$. D, Total numbers of neurons that were dual-IR for CTb/c-Fos, and triple-IR for CTb/c-Fos/prodynorphin. There was significantly more MDH neurons dual-IR in group ABB compared with group $A B A$. Importantly, there were significantly more triple-IR neurons in group $A B B$ compared with group $A B A .{ }^{*} p<0.05$ comparing group $A B B$ to $A B A$. $E$, Responses on active and inactive nose pokes during extinction (left) or test (right). Rats were trained in context $A$, extinguished in context $B$, and then tested in context A after infusions of either vehicle (VEH) or $\kappa$ opioid receptor agonist U50488. Rats with PVT infusions of U50488 showed a significant reduction in responding on the active nose poke compared with vehicle infusions. ${ }^{*} p<0.05$ comparing group U50488 to vehicle. Data are expressed as mean ( \pm SEM).

PVT microinjection of a $\kappa$ opioid agonist prevents reinstatement of reward seeking

Prodynorphin-expressing MDH neurons projecting to PVT are recruited during extinction expression. The actions of prodynorphin peptide(s) at opioid receptors in PVT may therefore be critical for inhibiting alcoholic beer seeking during extinction expression. The prodynorphin precursor encodes three opioid peptides, dynorphin $\mathrm{A}$, dynorphin $\mathrm{B}$ and neoendorphin, that each show high affinity for the $\kappa$ opioid receptor (KOR) (Wil- 

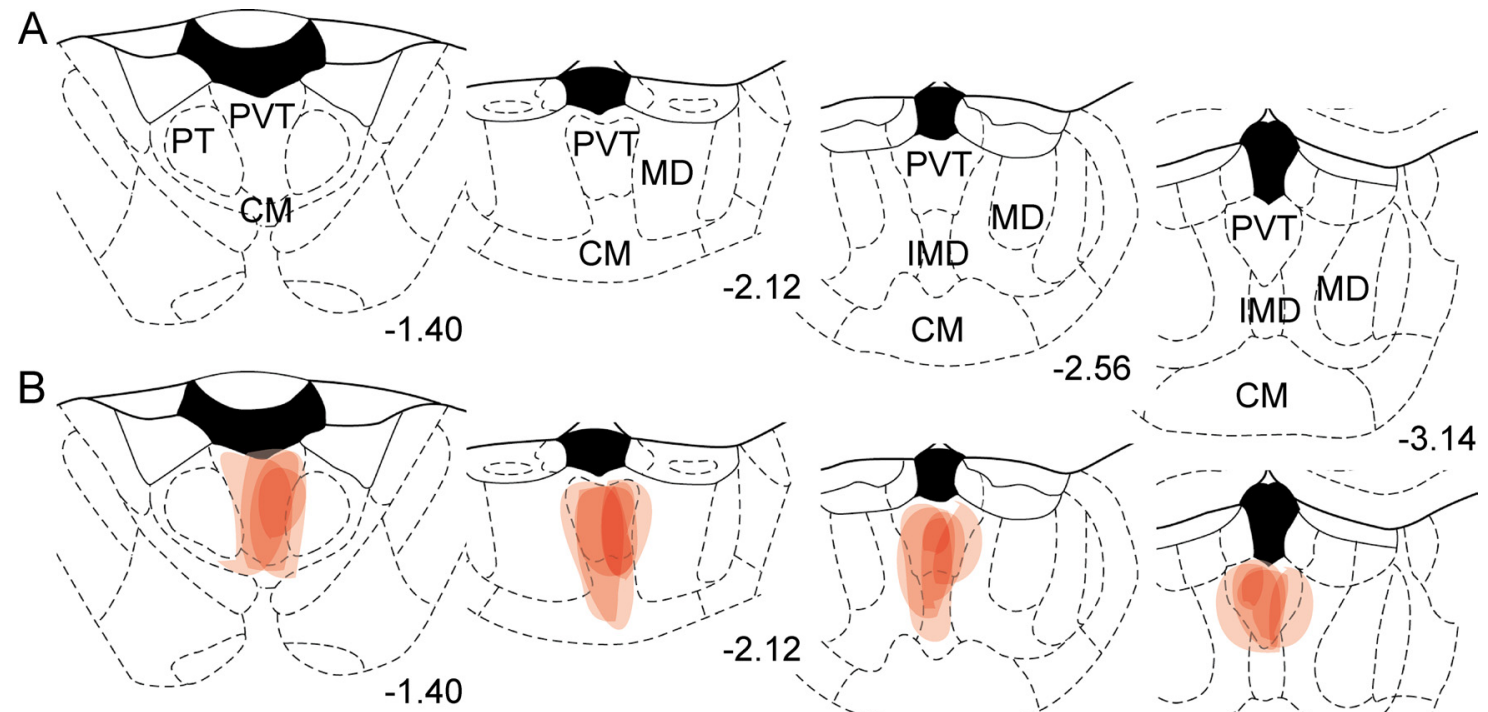

$-1.40$

$-2.12$
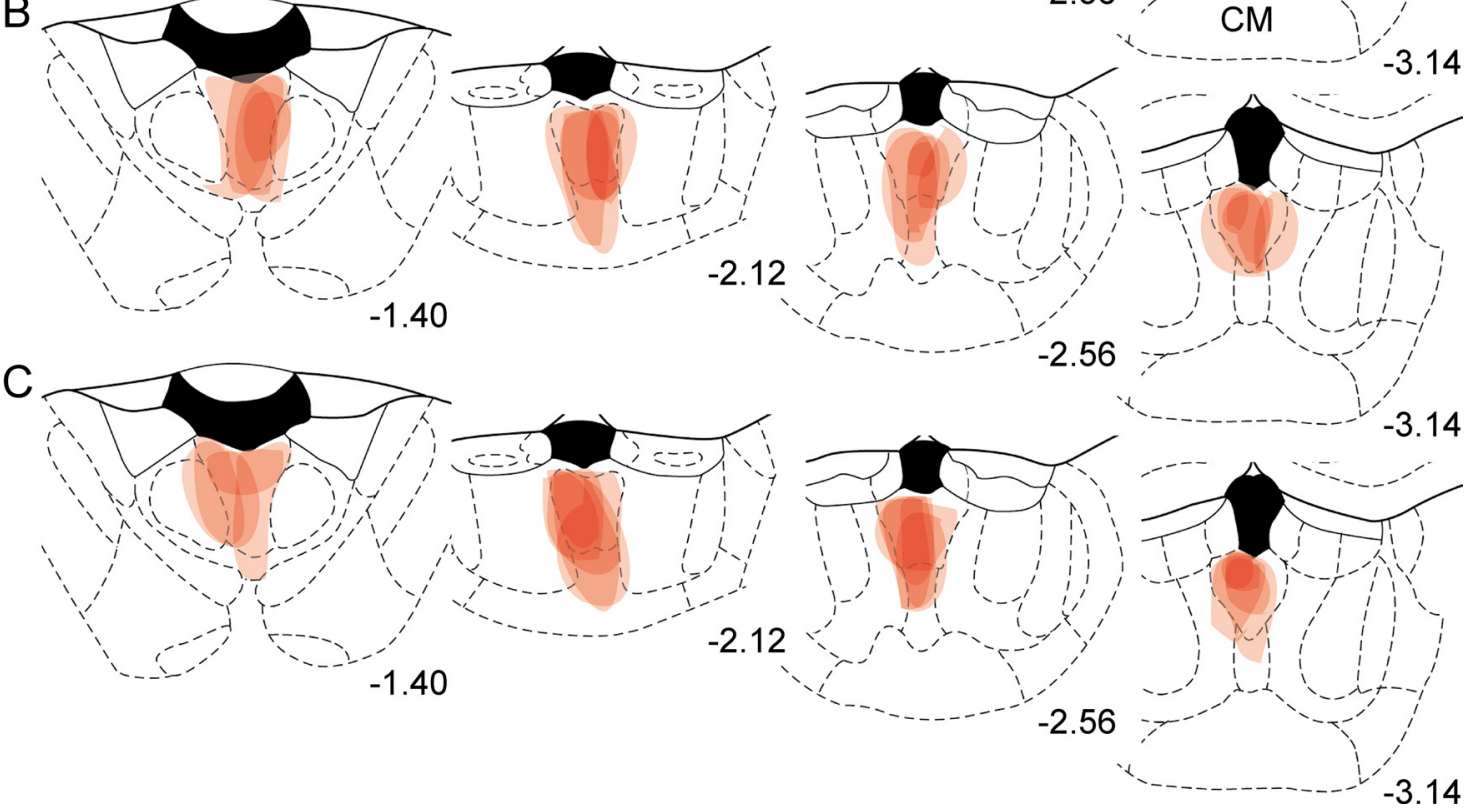

Figure 7. Schematic drawings through thalamus of the location of (Tb injections in PVT in triple-IR experiment. $A$, Four different stereotaxic levels adapted from Paxinos and Watson (1997) where correct CTb injections were confirmed with immunohistochemistry. $\boldsymbol{B}, \boldsymbol{C}$, Individual cases from group ABA $(\boldsymbol{B})$ and group $A B B(\boldsymbol{C})$ are plotted through the four levels. Numbers represent mm from bregma. Each injection is plotted at $25 \%$ opacity so that overlap of injection sites is apparent with increased color intensity. CM, central medial thalamic nucleus; IMD, intermediodorsal thalamic nucleus; MD, mediodorsal thalamic nucleus; PT, paratenial thalamic nucleus.

liams et al., 2001; McNally and Akil, 2002) and KOR mRNA is expressed at high levels in PVT (Mansour et al., 1994). If PVT $\kappa$ opioid receptors are critical for extinction expression then microinjections of a KOR agonist into PVT should mimic extinction expression and so inhibit reinstatement. To test this possibility rats were trained to respond for $4 \%$ alcoholic beer in context $\mathrm{A}$ before extinction training in context $\mathrm{B}$. After extinction, rats were tested for context-induced reinstatement in context A. Before this test rats received PVT infusions of the KOR agonist U50488 $(n=6)$ or vehicle $(n=6)$. PVT is a small structure. As such, we targeted our PVT injections toward the medial edge of PVT to avoid damaging PVT neurons. Importantly, expression of KOR mRNA at this rostral-caudal level is restricted to PVT (Mansour et al., 1994). We studied the effects of the KOR agonist on context-induced reinstatement, rather than the KOR antagonist on expression of extinction, because the optimal time to administer KOR antagonists to achieve behavioral effects remains unclear (Knoll et al., 2007; Land et al., 2008).

The left panel of Figure $6 E$ shows responding during extinction and the right panel shows responding during test. There was evidence for context-induced reinstatement because there was more responding on test in the training context than on day 5 of extinction training $\left(F_{(1,10)}=17.5, p<0.05\right)$. There was a significant group $\times$ manipulanda interaction on test $\left(F_{(1,10)}=7.7, p<\right.$ 0.05), showing that PVT infusions of the KOR agonist U50488 prevented context-induced reinstatement. This effect was spe- cific to the active nose poke because PVT infusions of U50488 significantly reduced the number of active $\left(F_{(1,10)}=8.9, p<\right.$ $0.05)$ but not inactive nose pokes $\left(F_{(1,10)}<1, p>0.05\right)$ on test. These results show that PVT microinjections of U50488 prevent context-induced reinstatement and reveal that activity at PVT KOR is sufficient to inhibit alcoholic beer seeking.

\section{Histology}

Figure 8 shows injection cannula placements for all microinfusion experiments. The plotted points represent the ventral point of the cannula tract.

\section{Discussion}

The expression of extinction versus reinstatement depends on the circumstances of test. When tested in the extinction context, drug seeking is inhibited, but when tested in the training context, in the presence of stressors, drug-related stimuli, or the drug itself, drug seeking is reinstated. Extinction expression is an active process, dependent on ilPFC (Peters et al., 2008), but the neural circuits responsible for inhibiting drug and reward seeking during extinction expression, and the relationship between these circuits and those for reinstatement, are poorly understood.

We used complementary functional and neuroanatomical approaches to study the role of the medial dorsal hypothalamus $(\mathrm{MDH})$ in expression of extinction of reward seeking. Combining retrograde tracing, using $\mathrm{CTb}$, with the marker of activation, 

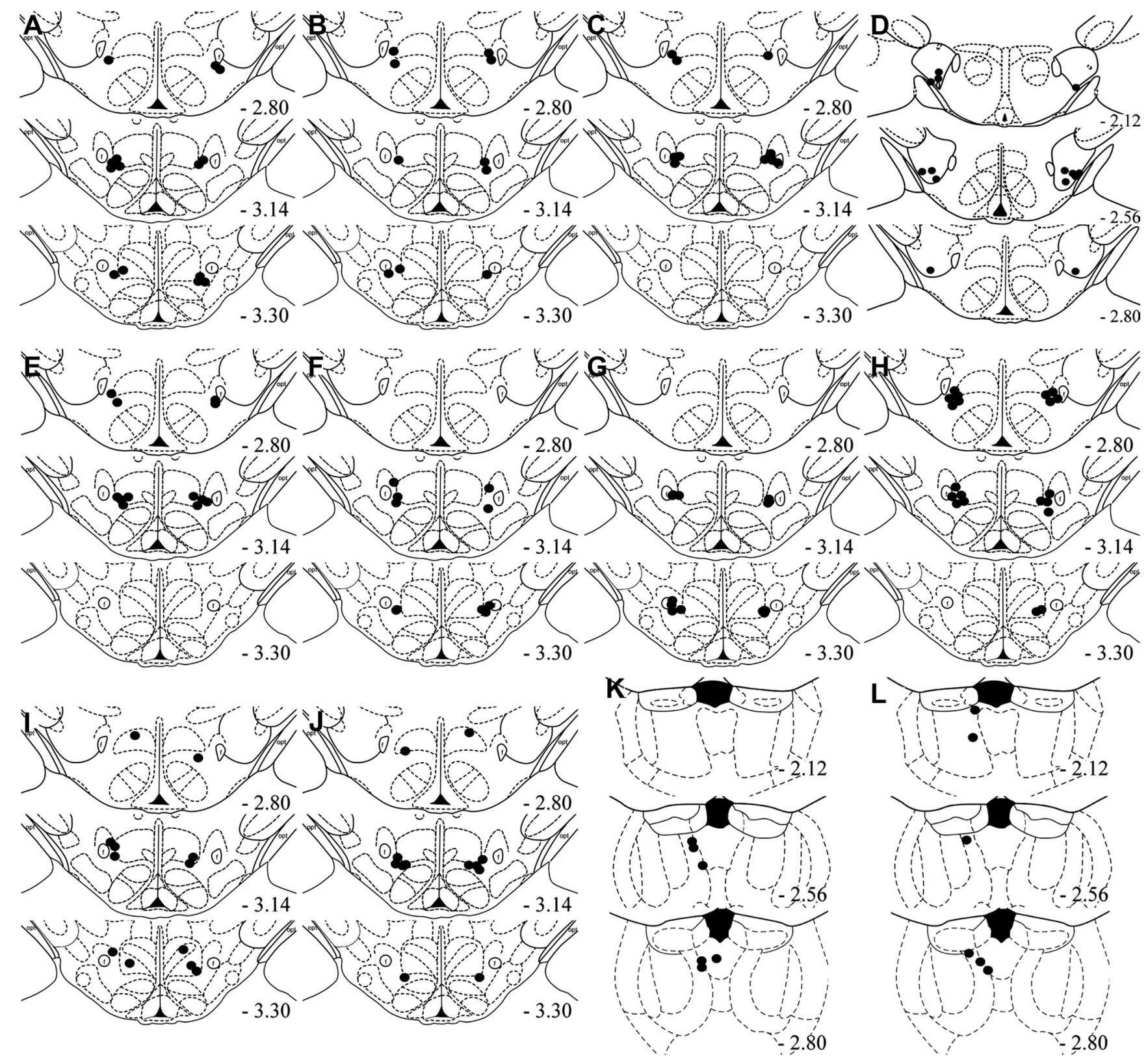

Figure 8. Cannula placement of all microinfusion experiments. Microinfusion cannula placements as verified on Nissl-stained sections for group MDH CART 55-102 tested for extinction (A), MDH vehicle tested for extinction (B), MDH CART 1-27 tested for extinction (C), LH CART 55-102 tested for extinction (D), MDH CART 55-102 untrained (E), MDH CART 55-102 tested for reinstatement ( $\boldsymbol{F}$ ), MDH vehicle tested for reinstatement $(\boldsymbol{G})$, MDH CART 55-102 dose-response $(\boldsymbol{H})$, MDH CART 55-102 trained for sucrose $(\boldsymbol{I})$, MDH vehicle trained for sucrose $(\boldsymbol{J})$, PVT U50488 tested for reinstatement $(K)$, PVT vehicle tested for reinstatement $(\boldsymbol{L})$. The symbols represent the most ventral point of the cannula track for each rat on coronal sections based on the atlas of Paxinos and Watson (1997).

c-Fos, we found that ilPFC neurons were active during expression of extinction and that direct projections from ilPFC to MDH are recruited during extinction expression. This was specific to ilPFC because other cortical and thalamic afferents to $\mathrm{MDH}$ did not show this effect. Activity in ilPFC is required for inhibiting drug seeking during extinction expression (Peters et al., 2008) and our results show that the expression of extinction is associated with activation of ilPFC projections to MDH. Projections from ilPFC are likely glutamatergic, suggesting that increased activation of ilPFC neurons during extinction may increase activity in $\mathrm{MDH}$. Given that reinstatement of drug seeking is the absence of extinction expression (Bouton, 2002), we tested whether pharmacological manipulation of $\mathrm{MDH}$ could inhibit extinction expression, resulting in reinstatement of extinguished reward seeking. We found that MDH infusions of the inhibitory neuropeptide CART
55-102 prevented extinction expression in a dose-dependent manner. This effect of CART55-102 was also detected on expression of extinguished sucrose seeking. The prevention of extinction expression was specific to the active CART fragment, CART 55-102, and was not observed with the inactive CART fragment, CART 1-27. It was also was anatomically specific to MDH because LH infusions of CART 55-102 did not affect extinction expression. CART 55-102 infusions were only effective when rats were tested in the extinction context. We observed no increase in responding in rats tested for context-induced reinstatement, in rats with no prior self-administration training, or in rats tested for self-administration. These findings suggest that the increase in responding in the extinction context was not secondary to any nonspecific effects of the CART infusions. Rather, these findings are consistent with the claim that MDH infusions of CART 55- 
102 selectively prevented expression of extinction of alcoholic beer seeking.

Extinction expression recruits direct projections from $\mathrm{MDH}$ to PVT. The majority of these $\mathrm{MDH}$ extinction neurons projecting to PVT expressed the opioid propeptide prodynorphin whose peptide products bind to the KOR. While the expression of c-Fos does not necessarily indicate transmitter release, activation of this pathway suggests that activation of KORs in PVT is sufficient to inhibit alcoholic beer seeking during extinction expression. Consistent with this, microinjections of the KOR agonist U50488 into PVT inhibited context-induced reinstatement. Activation of KORs is inhibitory (Childers, 1991), and KOR mRNA expression in PVT is high (Mansour et al., 1994). PVT is uniquely positioned to coordinate reinstatement through glutamatergic projections to many of the structures implicated in reinstatement, such as AcbSh, PFC, ventral subiculum, and BLA (Berendse and Groenewegen, 1990; Moga et al., 1995; Li and Kirouac, 2008). Context-induced reinstatement of alcoholic beer seeking is abolished by lesions of PVT (Hamlin et al., 2009). Furthermore, this reinstatement is associated with increased c-Fos expression specifically in PVT neurons projecting to AcbSh (Hamlin et al., 2009). Inhibition of PVT by MDH may be a critical mechanism for expression of extinction of alcoholic beer seeking.

The tuberal hypothalamus has historically been divided into lateral and medial hypothalamus based on contrasting effects of lesions of these regions on feeding behavior (Stellar, 1954). Recent evidence has confirmed this functional difference (Elmquist et al., 1999). When combined with recent findings (Marchant et al., 2009), the current results suggest similarly contrasting roles for $\mathrm{LH}$ and $\mathrm{MDH}$ in regulating drug and reward seeking. $\mathrm{LH}$ is critical for initiation of motivated behavior, including reinstatement of drug seeking (Kelley, 2004; Harris et al., 2005). Whereas $\mathrm{MDH}$ is critical for inhibition of motivated behavior, such as feeding (Elmquist et al., 1998; Kobelt et al., 2006) and LH intracranial self stimulation (Porrino et al., 1983). This study identifies an additional role for $\mathrm{MDH}$, mediating the expression of extinction of alcoholic beer seeking.

The opposing roles for medial versus lateral hypothalamic regions in expression of extinction versus context-induced reinstatement of alcoholic beer seeking may be a function of the neural networks in which they are embedded. Projections from PVT to AcbSh (Hamlin et al., 2009), and projections from AcbSh to LH (Marchant et al., 2009) are recruited during contextinduced reinstatement of alcoholic beer seeking. This LH contribution to reinstatement may depend, in turn, on projections to midbrain dopamine neurons (Aston-Jones et al., 2009). MDH appears to sit within a neural network with multiple potential sites for inhibitory control over circuits for reinstatement (Fig. 9). $\mathrm{MDH}$ does not receive any direct projections from striatum (Thompson and Swanson, 1998; Marchant et al., 2009) and instead receives direct projections from ilPFC which we found were recruited during expression of extinction. $\mathrm{MDH}$, in turn, projects to PVT during expression of extinction. Thus, PVT is one potential locus of convergence between circuits controlling extinction and reinstatement. AcbSh may be another. AcbSh mediates expression of extinction (Peters et al., 2008; Millan et al., 2010) and also reinstatement (Fuchs et al., 2008). Peters et al. (2008) showed that AcbSh contributions to extinction expression depended on ilPFC but we did not observe recruitment of direct ilPFC projections to AcbSh during extinction expression (Hamlin et al., 2009). However, an indirect projection from ilPFC to AcbSh could be recruited: $\mathrm{MDH}$ projects to dorsomedial AcbSh (our unpublished observations; Thompson et al., 1996) and dorsome-

\section{Test in extinction context \\ Extinction expression}

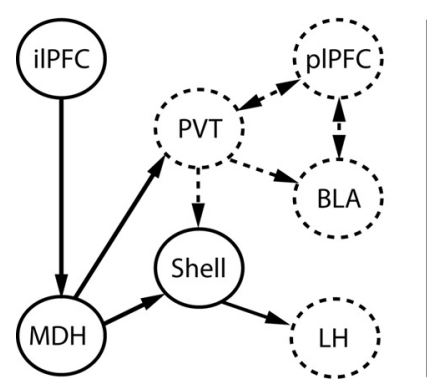

Test in training context Reinstatement

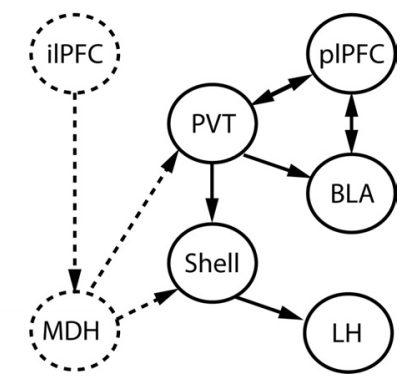

Figure 9. Possible circuit level mechanisms for expression of extinction versus contextinduced reinstatement. When rats are tested in the extinction context, alcoholic beer seeking is inhibited but when tested in the training context, alcoholic beer seeking is reinstated. Extinction expression is associated with activated projections from ilPFC to MDH. Activation of this pathway is proposed to inhibit alcoholic beer seeking via two pathways. First, prodynorphin projections from MDH to PVT are recruited during test in the extinction context, and signaling via PVT KORs may reduce glutamatergic PVT output to $\mathrm{pIPFC}, \mathrm{BLA}$, and accumbens shell (Shell). Second, projections from shell to $\mathrm{LH}$ are also recruited when rats are returned to the extinction context (Marchant et al., 2009). MDH may also modulate shell via direct projections as indicated; however, the functional significance of this pathway remains to be shown.

dial AcbSh projections to LH are recruited during extinction expression (Marchant et al., 2009).

It is worth considering whether common or unique circuits mediate extinction expression across different reinforcers (natural versus drug) and routes of administration (oral versus intravenous). Our data indicate recruitment of ilPFC during extinction expression based on alcoholic beer (Fig. 1) and ilPFC contributes to extinction expression based on intravenous cocaine (Peters et al., 2008). Likewise, AcbSh contributes to extinction expression based on intravenous cocaine (Peters et al., 2008) and alcoholic beer (Millan et al., 2010). LH contributions to reinstatement generalize across rewards as shown by reversible inactivation and neuronal activation (Harris et al., 2005; Hamlin et al., 2006, 2007, 2008; Marchant et al., 2009). Our finding for a role of $\mathrm{MDH}$ in expression of extinction of alcoholic beer and sucrose seeking is consistent with past research showing that stimulation of MDH inhibits LH self stimulation (Porrino et al., 1983). Thus, the available evidence suggests that there may be commonalities in the neural circuits controlling extinction expression across different reinforcers. However, the extent of this generalization remains an important empirical question.

Our tracing results show recruitment of an ilPFC $\rightarrow \mathrm{MDH}$ pathway and an $\mathrm{MDH} \rightarrow$ PVT pathway during expression of extinction. There are at least two important caveats on interpretation of these findings. First, in the absence of transsynaptic tracing (Kampe et al., 2009), it is not possible to determine whether the same MDH neurons receive ilPFC inputs and project to PVT during extinction expression, resulting in a direct ilPFC $\rightarrow \mathrm{MDH} \rightarrow$ PVT extinction pathway, or whether separate $\mathrm{MDH}$ neurons contribute to these pathways. Second, although we identified PVT as one target for MDH neurons during expression of extinction, PVT projecting neurons represented $\sim 20 \%$ of $\mathrm{MDH}$ neurons recruited during extinction expression. It is likely that other MDH efferents are recruited during extinction expression. Finally, while the majority of $\mathrm{MDH}$ neurons positive for both $\mathrm{CTb}$ and c-Fos also expressed prodynorphin, there were $\mathrm{CTb} / \mathrm{c}-$ Fos-expressing neurons that were not prodynorphin positive. This suggests that there may be contribution of non-prody- 
norphin-positive neurons to the expression of extinction, however the phenotype of these neurons is not known.

In conclusion, we have shown that the expression of extinction of alcoholic beer seeking recruits ilPFC $\rightarrow \mathrm{MDH}$ and $\mathrm{MDH} \rightarrow$ PVT pathways. Activation of these cortico-hypothalamic and hypothalamicthalamic pathways is associated with the inhibition of responding observed during extinction expression. Furthermore we provide evidence that $\mathrm{MDH}$ is causally important for expression of extinction. Microinjections of CART 55-102 into MDH selectively prevented extinction expression. This role for $\mathrm{MDH}$ in extinction expression complements the role previously described for $\mathrm{LH}$ in reinstatement of drug and reward seeking, suggesting that hypothalamus plays a critical role in initiating as well as inhibiting drug and reward seeking. Behavioral studies have shown that after extinction training, the memory from original training promoting relapse and the extinction memory promoting abstinence coexist and compete for control over motivation and behavior (Rescorla, 2001; Bouton, 2002). This competition between extinction/abstinence and reinstatement/relapse may be determined by competition between neural circuits involving MDH to promote abstinence versus neural circuits involving LH to promote relapse.

\section{References}

Abbott CR, Rossi M, Wren AM, Murphy KG, Kennedy AR, Stanley SA, Zollner AN, Morgan DG, Morgan I, Ghatei MA, Small CJ, Bloom SR (2001) Evidence of an orexigenic role for cocaine- and amphetamineregulated transcript after administration into discrete hypothalamic nuclei. Endocrinology 142:3457-3463.

Aston-Jones G, Smith RJ, Moorman DE, Richardson KA (2009) Role of lateral hypothalamic orexin neurons in reward processing and addiction. Neuropharmacology 56:112-121.

Bellinger LL, Bernardis LL (2002) The dorsomedial hypothalamic nucleus and its role in ingestive behavior and body weight regulation: Lessons learned from lesioning studies. Physiol Behav 76:431-442.

Berendse HW, Groenewegen HJ (1990) Organization of the thalamostriatal projections in the rat, with special emphasis on the ventral striatum. J Comp Neurol 299:187-228.

Bouton ME (2002) Context, ambiguity, and unlearning: sources of relapse after behavioral extinction. Biol Psychiatry 52:976-986.

Boutrel B, Kenny PJ, Specio SE, Martin-Fardon R, Markou A, Koob GF, de Lecea L (2005) Role for hypocretin in mediating stress-induced reinstatement of cocaine-seeking behavior. Proc Natl Acad Sci U S A 102:19168-19173.

Carroll ME (1985) The role of food deprivation in the maintenance and reinstatement of cocaine-seeking behavior in rats. Drug Alcohol Depend 16:95-109.

Chen J, Scott KA, Zhao Z, Moran TH, Bi S (2008) Characterization of the feeding inhibition and neural activation produced by dorsomedial hypothalamic cholecystokinin administration. Neuroscience 152:178-188.

Childers SR (1991) Opioid receptor-coupled second messenger systems. Life Sci 48:1991-2003.

Christie MJ, Summers RJ, Stephenson JA, Cook CJ, Beart PM (1987) Excitatory amino acid projections to the nucleus accumbens septi in the rat: a retrograde transport study utilizing $\mathrm{D}\left[{ }^{3} \mathrm{H}\right]$ aspartate and $\left[{ }^{3} \mathrm{H}\right] \mathrm{GABA}$. Neuroscience 22:425-439.

Comer SD, Lac ST, Wyvell CL, Curtis LK, Carroll ME (1995) Food deprivation affects extinction and reinstatement of responding in rats. Psychopharmacology 121:150-157.

Conklin CA, Tiffany ST (2002) Applying extinction research and theory to cue-exposure addiction treatments. Addiction 97:155-167.

Dayas CV, McGranahan TM, Martin-Fardon R, Weiss F (2008) Stimuli linked to ethanol availability activate hypothalamic CART and orexin neurons in a reinstatement model of relapse. Biol Psychiatry 63:152-157.

Elmquist JK, Ahima RS, Elias CF, Flier JS, Saper CB (1998) Leptin activates distinct projections from the dorsomedial and ventromedial hypothalamic nuclei. Proc Natl Acad Sci U S A 95:741-746.

Elmquist JK, Elias CF, Saper CB (1999) From lesions to leptin: hypothalamic control of food intake and body weight. Neuron 22:221-232.

Fuchs RA, Ramirez DR, Bell GH (2008) Nucleus accumbens shell and core involvement in drug context-induced reinstatement of cocaine seeking in rats. Psychopharmacology 200:545-556.

Hamlin AS, Blatchford KE, McNally GP (2006) Renewal of an extinguished instrumental response: neural correlates and the role of D1 dopamine receptors. Neuroscience 143:25-38.

Hamlin AS, Newby J, McNally GP (2007) The neural correlates and role of D1 dopamine receptors in renewal of extinguished alcohol-seeking. Neuroscience 146:525-536.

Hamlin AS, Clemens KJ, McNally GP (2008) Renewal of extinguished cocaine-seeking. Neuroscience 151:659-670.

Hamlin AS, Clemens KJ, Choi EA, McNally GP (2009) Paraventricular thalamus mediates context-induced reinstatement (renewal) of extinguished reward seeking. Eur J Neurosci 29:802-812.

Harris GC, Wimmer M, Aston-Jones G (2005) A role for lateral hypothalamic orexin neurons in reward seeking. Nature 437:556-559.

Harris GC, Wimmer M, Randall-Thompson JF, Aston-Jones G (2007) Lateral hypothalamic orexin neurons are critically involved in learning to associate an environment with morphine reward. Behav Brain Res 183:43-51.

Harris RJ (1994) ANOVA: an analysis of variance primer. Itasca, IL: Peacock.

Heidbreder CA, Groenewegen HJ (2003) The medial prefrontal cortex in the rat: evidence for a dorso-ventral distinction based upon functional and anatomical characteristics. Neurosci Biobehav Rev 27:555-579.

Hoebel BG (1979) Hypothalamic self-stimulation and stimulation escape in relation to feeding and mating. Fed Proc 38:2454-2461.

Kampe J, Tschöp MH, Hollis JH, Oldfield BJ (2009) An anatomic basis for the communication of hypothalamic, cortical and mesolimbic circuitry in the regulation of energy balance. Eur J Neurosci 30:415-430.

Kelley AE (2004) Ventral striatal control of appetitive motivation: role in ingestive behavior and reward-related learning. Neurosci Biobehav Rev 27:765-776.

Kirouac GJ, Parsons MP, LiS (2005) Orexin (hypocretin) innervation of the paraventricular nucleus of the thalamus. Brain Res 1059:179-188.

Kirouac GJ, Parsons MP, Li S (2006) Innervation of the paraventricular nucleus of the thalamus from cocaine- and amphetamine-regulated transcript (CART) containing neurons of the hypothalamus. J Comp Neurol 497:155-165.

Knoll AT, Meloni EG, Thomas JB, Carroll FI, Carlezon WA Jr (2007) Anxiolytic-like effects of kappa-opioid receptor antagonists in models of unlearned and learned fear in rats. J Pharmacol Exp Ther 323:838-845.

Kobelt P, Paulitsch S, Goebel M, Stengel A, Schmidtmann M, van der Voort IR, Tebbe JJ, Veh RW, Klapp BF, Wiedenmann B, Táche Y, Mönnikes H (2006) Peripheral injection of CCK-8S induces Fos expression in the dorsomedial hypothalamic nucleus in rats. Brain Res 1117:109-117.

Land BB, Bruchas MR, Lemos JC, Xu M, Melief EJ, Chavkin C (2008) The dysphoric component of stress is encoded by activation of the dynorphin \{kappa\}-opioid System. J Neurosci 28:407-414.

Lawrence AJ, Cowen MS, Yang HJ, Chen F, Oldfield B (2006) The orexin system regulates alcohol-seeking in rats. Br J Pharmacol 148:752-759.

Li S, Kirouac GJ (2008) Projections from the paraventricular nucleus of the thalamus to the forebrain, with special emphasis on the extended amygdala. J Comp Neurol 506:263-287.

Mansour A, Fox CA, Meng F, Akil H, Watson SJ (1994) [kappa]1 receptor mRNA distribution in the rat CNS: comparison to [kappa] receptor binding and prodynorphin mRNA. Mol Cell Neurosci 5:124-144.

Marchant NJ, Hamlin AS, McNally GP (2009) Lateral hypothalamus is required for context-induced reinstatement of extinguished reward seeking. J Neurosci 29:1331-1342.

McNally GP, Akil H (2002) Opioid peptides and their receptors. In: Neuropsychopharmacology: fifth generation of progress, Ed 5 (Davis K, Charney D, Coyle JT, Nemeroff C, eds), pp 35-46. New York: Lippincott Williams \& Wilkins.

Millan EZ, Furlong TM, McNally GP (2010) Accumbens shell-hypothalamus interactions mediate extinction of alcohol seeking. J Neurosci 30:4626-4635.

Moga MM, Weis RP, Moore RY (1995) Efferent projections of the paraventricular thalamic nucleus in the rat. J Comp Neurol 359:221-238.

O'Brien RG, Kaiser MK (1985) MANOVA method for analyzing repeated measures designs: an extensive primer. Psychol Bull 97:316-333.

Pavlov IP (1927) Conditioned reflexes: an investigation of the physiological activity of the cerebral cortex. London: Oxford University. 
Paxinos G, Watson C (1997) The rat brain in stereotaxic coordinates, Ed 3. San Diego: Academic.

Peters J, LaLumiere RT, Kalivas PW (2008) Infralimbic prefrontal cortex is responsible for inhibiting cocaine seeking in extinguished rats. J Neurosci 28:6046-6053.

Pirnik Z, Maixnerová J, Matysková R, Koutová D, Zelezná B, Maletínská L, Kiss A (2010) Effect of anorexinergic peptides, cholecystokinin (CCK) and cocaine and amphetamine regulated transcript (CART) peptide, on the activity of neurons in hypothalamic structures of C57BL/6 mice involved in the food intake regulation. Peptides 31:139-144.

Porrino LJ, Coons EE, MacGregor B (1983) Two types of medial hypothalamic inhibition of lateral hypothalamic reward. Brain Res 277:269-282.

Rescorla RA (2001) Experimental extinction. In: Handbook of contemporary learning theories (Mowrer RM, Klein SB, eds), pp 119-154. Mahwah, NJ: Erlbaum.

Rogge G, Jones D, Hubert GW, Lin Y, Kuhar MJ (2008) CART peptides: regulators of body weight, reward and other functions. Nat Rev Neurosci 9:747-758.
Shalev U, Highfield D, Yap J, Shaham Y (2000) Stress and relapse to drug seeking in rats: studies on the generality of the effect. Psychopharmacology (Berl) 150:337-346.

Stein J, Steiner DF, Dey A (2006) Processing of cocaine- and amphetamineregulated transcript (CART) precursor proteins by prohormone convertases (PCs) and its implications. Peptides 27:1919-1925.

Stellar E (1954) The physiology of motivation. Psychol Rev 61:5-22.

Thompson RH, Swanson LW (1998) Organization of inputs to the dorsomedial nucleus of the hypothalamus: a reexamination with Fluorogold and PHAL in the rat. Brain Res Brain Res Rev 27:89-118.

Thompson RH, Canteras NS, Swanson LW (1996) Organization of projections from the dorsomedial nucleus of the hypothalamus: a PHA-L study in the rat. J Comp Neurol 376:143-173.

Vertes RP, Hoover WB (2008) Projections of the paraventricular and paratenial nuclei of the dorsal midline thalamus in the rat. J Comp Neurol 508:212-237.

Williams JT, Christie MJ, Manzoni O (2001) Cellular and synaptic adaptations mediating opioid dependence. Physiol Rev 81:299-343. 